Universidad de Lima

Facultad de Comunicación

Carrera de Psicología

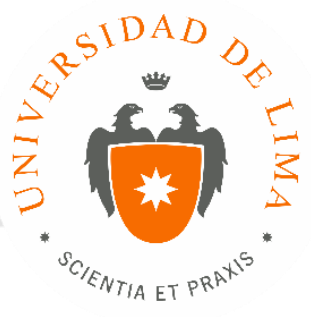

\title{
BURNOUT EN PROFESIONALES DE ESTABLECIMIENTOS DE SALUD DEL PRIMER NIVEL DE ATENCION DE LIMA METROPOLITANA
}

Tesis para optar el Título Profesional de Licenciado en Psicología

\section{Luis Ernesto Nunura Linares}

Código 20091285

\section{Asesor}

Mónica Guiselda Fernandez Otoya

$$
\text { Lima - Perú }
$$

Diciembre de 2016 


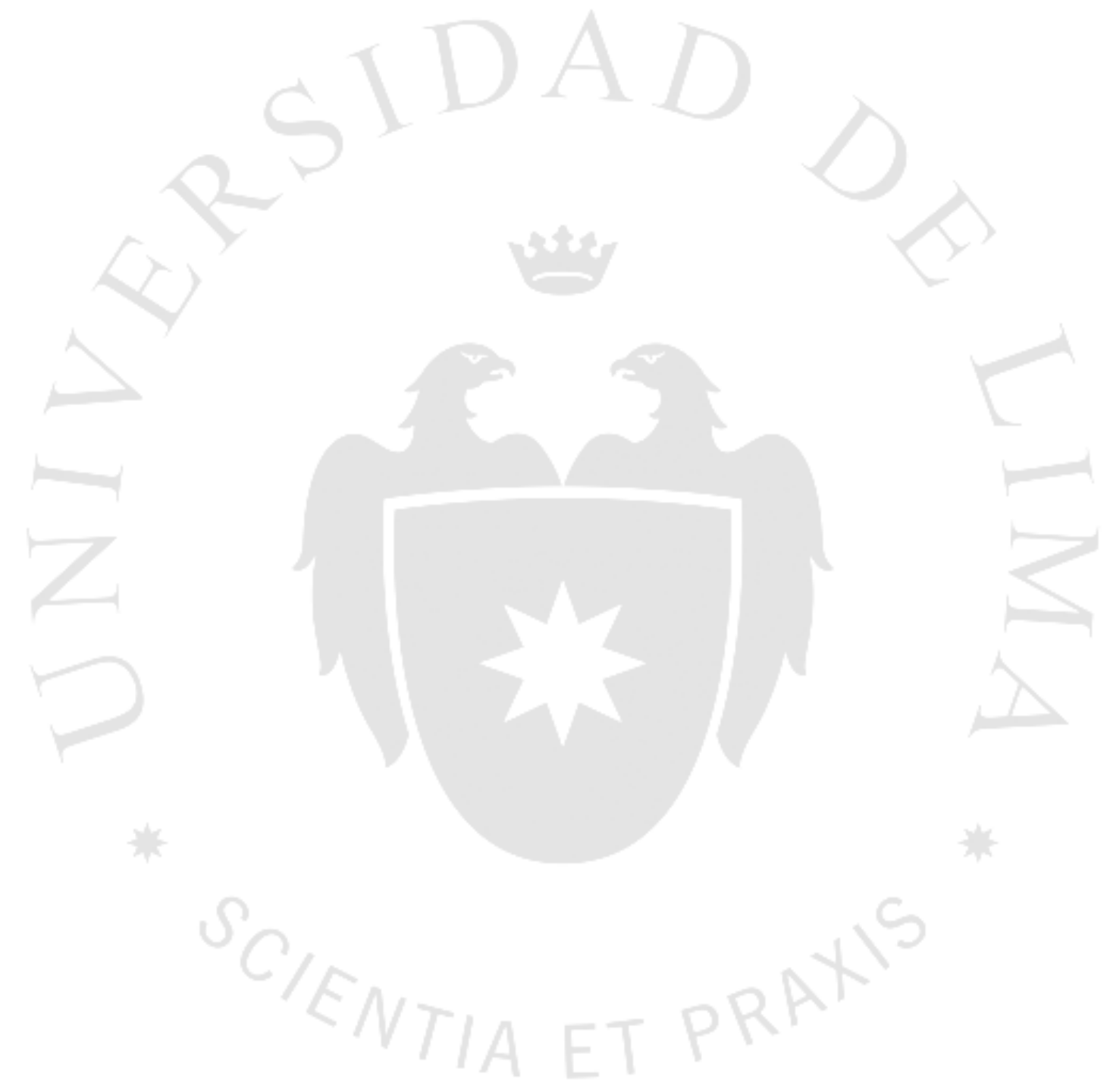




\section{AGRADECIMIENTOS}

El burnout o estrés laboral es un tema que me interesó desde los primeros ciclos de pregrado. Antes de estudiar Psicología, estudié Medicina Humana durante tres años y medio y viví muy de cerca los distintos estresores a los que están expuestos los profesionales de la salud, así como también presencié el ambiente complicado en el cuál se desempeñan. Además, mi madre es Doctora en Medicina y cuando le compartí la idea de profundizar sobre el tema del estrés laboral en su profesión, me apoyó desde el primer momento. Por otro lado, la construcción de mi investigación se la debo a muchas personas que me fueron acompañando y apoyando durante el proceso.

Me gustaría agradecer de manera especial a la Dra. Victoria Llaja, quien me brindó la autorización de utilizar el instrumento adaptado a la realidad peruana del Inventario de Burnout de Maslach y Jackson, y quien siempre estuvo dispuesta a aclarar cualquier duda que fue apareciendo en el camino. Dicha autorización fue el punto de partida de mi investigación y me permitió realizar la aplicación del instrumento en los centros de salud elegidos. Asimismo, me gustaría agradecer también a los Directores de los centros de salud que visité, pues sin su aprobación y buena disposición no hubiera podido recolectar la muestra necesaria para mi investigación.

Debo agradecer profundamente a los profesores Sandra Inurritegui, Noemí Salazar, Liz Pajares, Paola Lindo, Verónica Vargas y María del Carmen Espinoza, quienes me asesoraron cada vez que lo requerí, y me guiaron en la elaboración de mi investigación desde que la inicié. Adicionalmente, me gustaría reconocer el apoyo de los profesores Miguel Escurra y Andres Burga, quienes me guiaron desde el punto de vista estadístico. Su ayuda fue valiosa y me permitió adquirir conocimientos que pude aplicar al momento de elaborar los resultados de mi investigación.

Agradezco a la profesora Mónica Fernandez por haber sido mi asesora de investigación. Me permitió identificar los puntos que debía reforzar, y me motivo siempre a mejorar y darle una estructura sólida a mi trabajo. Su guía fue fundamental durante todo el proceso.

Por último, me gustaría agradecer al motor de mi vida: a mi familia, a mis abuelos, y a mi madre muy especialmente, quien es la persona más importante en mi 
vida y a quien le debo todo lo que soy. Ella me apoyó en todo momento, por lo cual le estaré eternamente agradecido. Este trabajo se lo dedico como parte del agradecimiento que quisiera darle por todo lo que me ha dado. 


\section{BURNOUT EN PROFESIONALES DE ESTABLECIMIENTOS DE SALUD DEL PRIMER NIVEL DE ATENCION DE LIMA METROPOLITANA}




\section{TABLA DE CONTENIDOS}

INTRODUCCION.............................................................1

CAPITULO I: PLANTEAMIENTO DEL PROBLEMA............................3

1.1 Descripción del problema.........................................

1.2 Justificación y relevancia..............................................

CAPITULO II: MARCO TEORICO ..................................................7

2.1 Conceptualización del síndrome de burnout..........................

2.2 Prevalencia del síndrome de burnout....................................8

2.3 Signos y Síntomas................................................ 16

2.4 Estadíos............................................................ 17

2.5 Desencadenantes del Burnout..........................................19

2.6 Efectos del burnout y manejo del síndrome...........................22

2.6.1 Efectos del burnout............................................22

2.6.2 Manejo del síndrome de burnout..................................23

2.7 El Rol de las variables situacionales en el síndrome de burnout.............26

2.8 Establecimientos de Salud...........................................29

2.8.1 Conceptualización y tipos de Establecimientos de Salud...............29

2.8.2 Tipos de Niveles de Atención...................................30

2.8.3 Policlínicos....................................................33

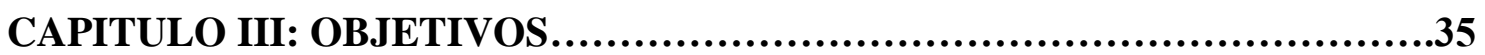

3.1 Objetivos..................................................... 35

3.2 Hipótesis..................................................... 35

3.3 Definición de variables............................................. 36 
CAPITULO IV: METODOLOGIA............................................38

4.1 Tipo y diseño de investigación....................................38

4.2 Participantes..................................................... 38

4.3 Técnicas de recolección de información..............................41

4.3.1 Descripción del instrumento....................................41

4.3.2 Confiabilidad y Validez.......................................44

4.3.2.1 Confiabilidad y Validez original....................................44

4.3.2.2 Confiabilidad y Validez en el Perú......................................45

4.4 Procedimiento de recolección de datos.............................47

CAPITULO V: RESULTADOS.............................................49

5.1 Niveles de Burnout...............................................49

5.2 Análisis de la Normalidad............................................51

5.3 Dimensiones de Burnout............................................55

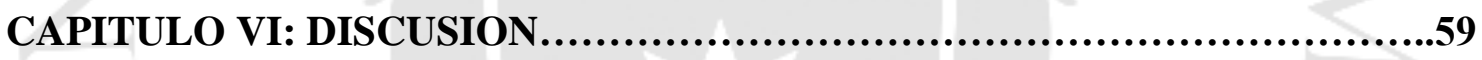

6.1 Descripción de los niveles de Burnout.................................60

6.2 Contraste de hipótesis de investigación.................................64

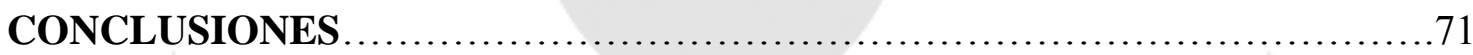

RECOMENDACIONES ................................................. 72

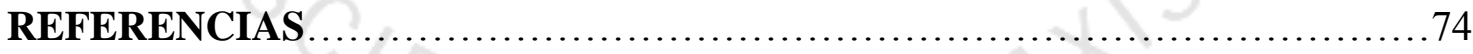

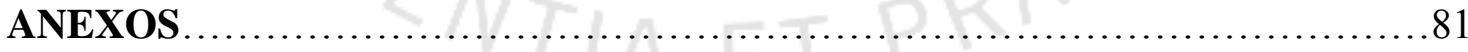




\section{INDICE DE TABLAS}

Tabla 1: Categorías de establecimientos de salud por niveles de atención..............31

Tabla 2: Denominación de establecimientos de salud según categoría.................32

Tabla 3: Categorías de establecimientos de salud a nivel nacional....................33

Tabla 4: Composición de la muestra .............................................40

Tabla 5: Composición de las áreas del Inventario de Burnout de Maslach..................42

Tabla 6: Niveles de Burnout de la muestra en general.................................49

Tabla 7: Niveles de Burnout según el sexo....................................50

Tabla 8: Niveles de Burnout según la profesión...................................50

Tabla 9: Niveles de Burnout según la jornada laboral.............................51

Tabla 10: Niveles de Burnout según el tiempo de servicio.......................51

Tabla 11: Análisis de Normalidad del MBI según sexo..................................52

Tabla 12: Análisis de la Normalidad del MBI según profesión.....................53

Tabla 13: Análisis de la Normalidad del MBI según jornada laboral.................54

Tabla 14: Análisis de la Normalidad del MBI según tiempo de servicio................55

Tabla 15: Comparación de medias para cada Dimensión del Burnout según el

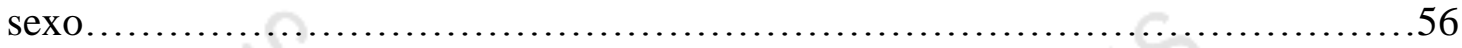

Tabla 16: Comparación de medias para cada Dimensión del Burnout según la profesión. 56

Tabla 17: Comparación de medias para cada Dimensión del Burnout según la jornada laboral

Tabla 18: Comparación de medias para cada Dimensión del Burnout según el tiempo de servicio .58 


\section{INDICE DE ANEXOS}

Anexo 1: Consentimiento Informado........................................ 82

Anexo 2: Ficha sociodemográfica............................................ 83

Anexo 3: Inventario de Burnout (adaptado por Llaja, Sarria y García, 2007)................84

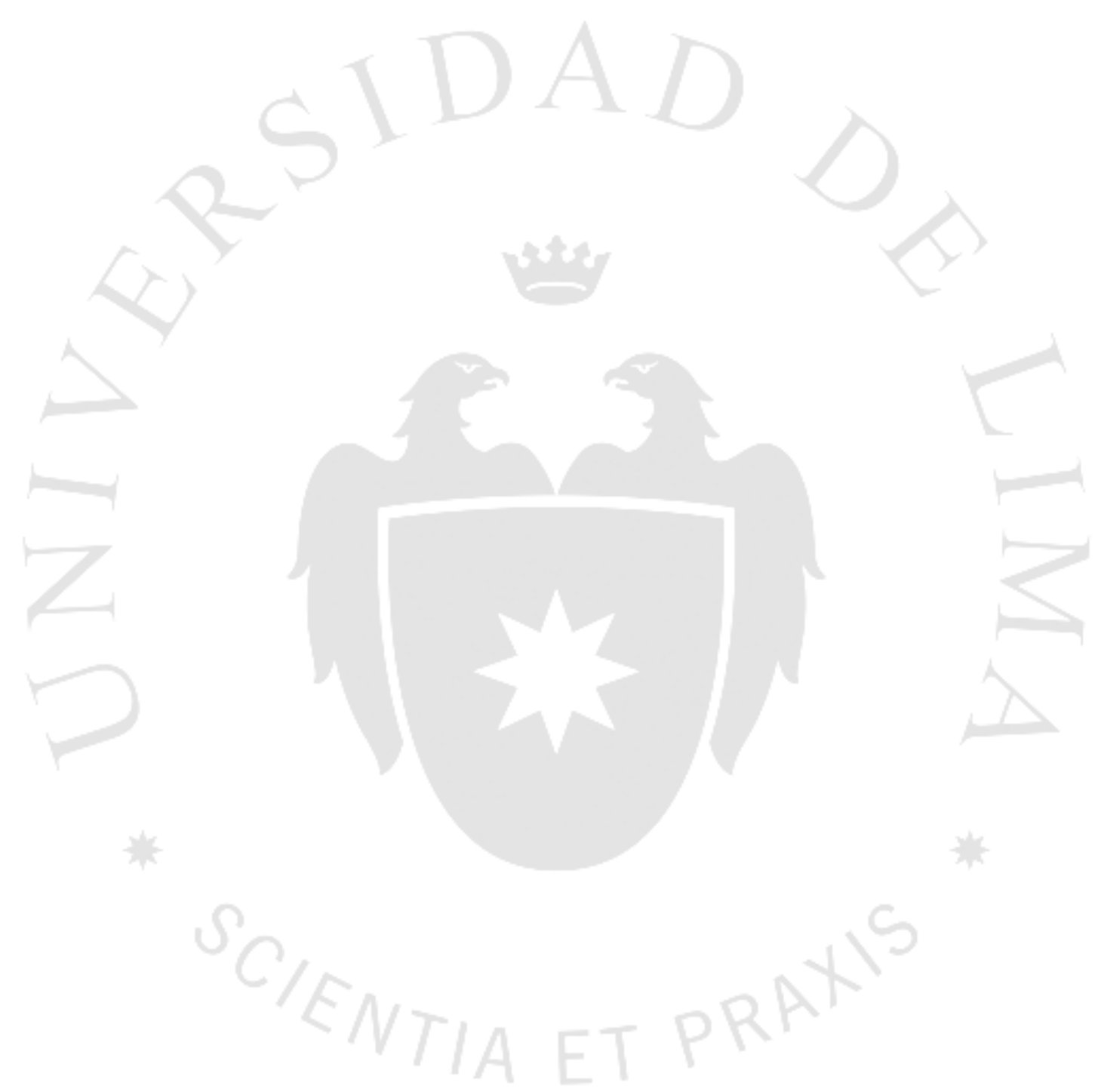




\section{RESUMEN}

Se presenta un trabajo de investigación sobre el Síndrome de Burnout y su presencia en profesionales de la salud de Policlínicos de Lima metropolitana. Los motivos que impulsan la realización de este estudio parten de la preocupación sobre el incremento del número de personas que presentan el síndrome y la poca investigación realizada en el área de la salud que se pueda aplicar al contexto peruano. Esta investigación se centró en hallar y describir los niveles del síndrome de Burnout en una muestra de 85 médicos y 41 enfermeras, los cuales fueron evaluados con el Inventario de Burnout de Maslach adaptado al contexto peruano por Victoria Llaja en el año 2007. La investigación tiene un enfoque cuantitativo y un alcance de tipo descriptivo comparativo. La muestra fue seleccionada de manera no probabilística por conveniencia. Además de hallar los niveles de Burnout en los participantes, se realizaron comparaciones entre las tres escalas del Burnout, (Agotamiento Emocional, Despersonalización, Reducida Realización Personal) según sexo, profesión, años de servicio, y horas de trabajo semanales. Los resultados comprueban la presencia del síndrome en la muestra estudiada y justifican la necesidad de intervenir en estos profesionales, a través de estrategias que les permitan afrontar las demandas que exigen sus profesiones, y de efectuar mejoras en las instituciones de salud.

Palabras clave: Síndrome de Burnout, Agotamiento Emocional, Despersonalización, Reducida Realización Personal. 


\begin{abstract}
The present research is about the burnout's syndrome and its presence in health professionals in metropolitan Lima Polyclinics. The reasons that drive this study are based on concerns about the increasing number of people with the syndrome and the limited research in the health area that can be applied to peruvian context.
\end{abstract}

This research focused on finding and describing levels of Burnout's syndrome in a sample of 85 doctors and 41 nurses, who were assessed with the Maslach Burnout Inventory adapted to peruvian context by Victoria Llaja in 2007. The research is descriptive comparative and has a quantitative approach. The sample was selected on a non-probabilistic way and by convenience.

Besides finding Burnout levels in participants, comparisons were made between the three scales of Burnout, (Emotional Weariness, Selflessness, Reduction of the personal Accomplishment) based on gender, profession, years of service and hours of work per week.

The results prove the presence of the syndrome in the study sample and justify the need to intervene in these professionals, providing them with strategies to face with the demands required by their professions and for improvements in health institutions.

Keywords: Burnout's Syndrome, Emotional Weariness, Selflessness, Reduction of the Personal Accomplishment. 


\section{INTRODUCCION}

Como todo trabajador, los profesionales de la salud forman parte de una organización, lo cual lleva consigo que los elementos que rodeen la labor de cada profesional, tengan una influencia directa en su accionar. Es decir, las condiciones de trabajo, y los estresores que estén presentes en el día a día del trabajador influirán en su conducta, desempeño y motivación personales.

Por esta razón, se decide realizar la presente investigación acerca de los niveles de Burnout o Estrés Laboral que presentan los profesionales de la salud, quienes constantemente están expuestos a estresores laborales. Es de gran importancia, el hecho de hacer una investigación adaptada al contexto peruano ya que de esta manera se podrá conocer de qué manera responden los profesionales al Sistema de Salud Pública en el Perú.

El describir e identificar los niveles de estrés que presenta la muestra estudiada permitirá ampliar el conocimiento que se tiene del Burnout en el contexto peruano. Así como también servirá para generar estrategias que sirvan como modelo en distintas instituciones de salud pública, y que gracias a esto se formule una actitud positiva frente al síndrome. Adicionalmente, se plantea la investigación con el propósito de obtener información acerca del nivel de agotamiento emocional que exhibe el profesional de la salud, así como del nivel de despersonalización y de realización personal, con la finalidad de enfocar las estrategias de intervención a cada dimensión.

La presente investigación está estructurada en seis capítulos a través de los cuales se presentan los distintos aspectos metodológicos y teóricos, los cuales constituyen la base al problema de investigación planteado, así como también se presentarán los resultados obtenidos y el abordaje hacia los mismos.

En el primer capítulo, se detalla el planteamiento del problema así como la pregunta de investigación, la justificación y relevancia.

El segundo capítulo, comprende la base teórica conceptual donde se describen y analizan las definiciones, enfoques y modelos relacionados. 
El tercer capítulo, presenta los objetivos de la investigación, la formulación de las hipótesis y la definición de las variables de estudio.

En el cuarto capítulo, se detallan los aspectos metodológicos de la investigación: tipo y diseño de la investigación, participantes, técnicas de recolección de la información y procedimiento adoptado en el presente estudio.

En el quinto capítulo, se presentan los resultados de acuerdo a los objetivos planteados. En estos se describen los niveles y escalas de Burnout en la muestra según las variables tomadas en cuenta.

Finalmente, se discuten los hallazgos del estudio, considerando los antecedentes de investigaciones y el marco teórico. A continuación se procedió a formular las conclusiones de la investigación, y las recomendaciones que se consideraron adecuadas.

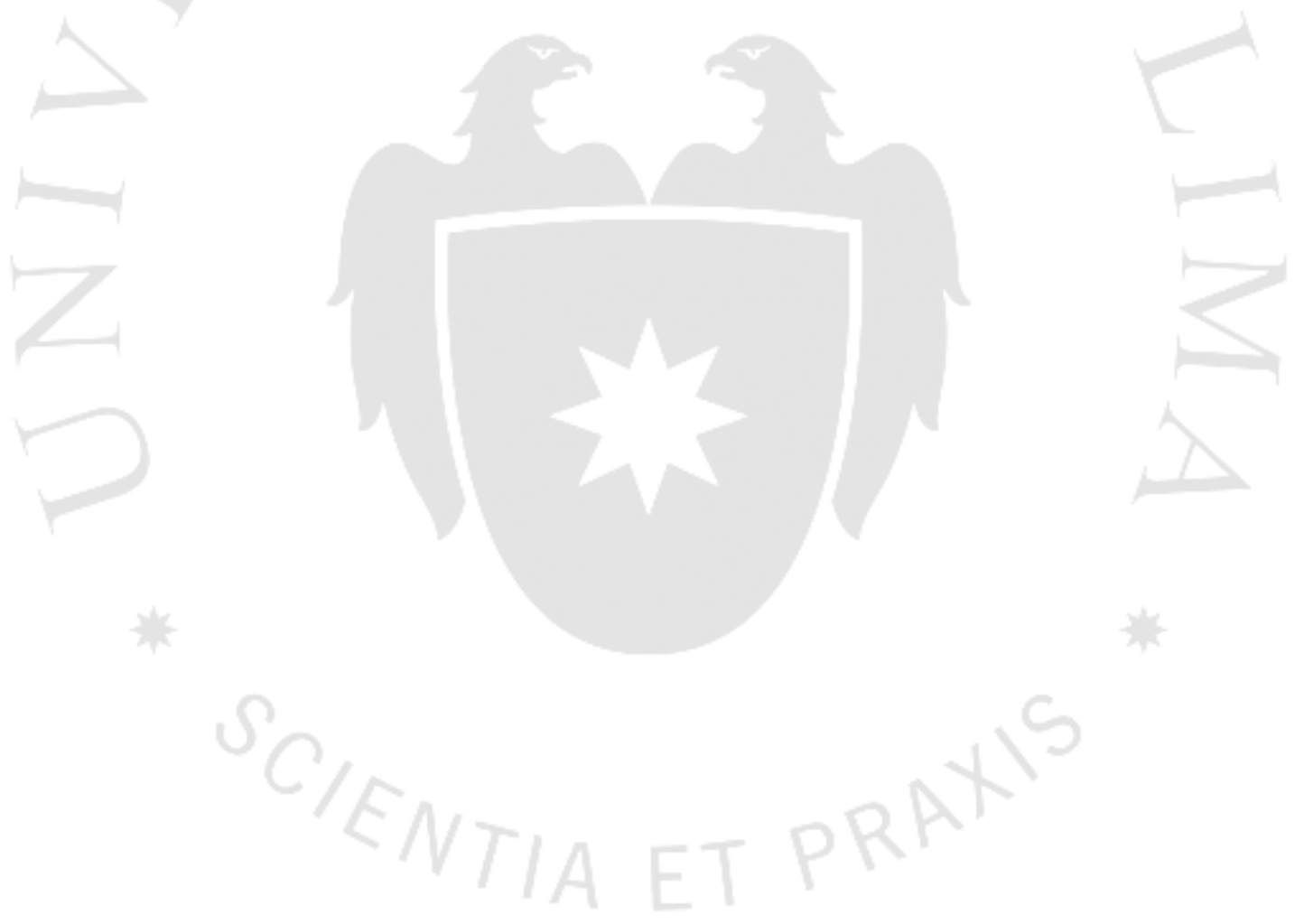




\section{CAPITUlO I: PLANTEAMIENTO DEL PROBLEMA}

\subsection{Descripción del problema}

En la actualidad las profesiones de servicio que se caracterizan por una atención intensa y prolongada hacia personas que están en una situación de necesidad o dependencia pueden devenir en un tipo de estrés crónico. Dicho estrés es una respuesta a los sucesos que amenazan o ponen en conflicto a quienes enfrentan situaciones demandantes (Fernández, 2008; Quintanilla, 2004).

Por otro lado, cuando el estrés moviliza de manera óptima a la persona, se habla de un estrés positivo, pero cuando trae repercusiones físicas y/o psicológicas se denomina estrés negativo. En el ámbito organizacional, cuando el estrés es resultado de variables presentes en el trabajo, se está ante la presencia de un estrés laboral.

El estrés laboral, según Karasek (1979) es una variable dependiente del efecto conjunto de las demandas de trabajo y los factores moderadores de las mismas, particularmente la percepción de control o grado de libertad de decisión del trabajador.

Tal definición hace énfasis en las demandas de trabajo y los factores moderadores, lo cual denota la presencia de estresores, entendidos como todo aquello que genera estrés. Ya sean estresores provenientes de fuentes externas o internas, la satisfacción laboral disminuye y se desarrollan actitudes negativas hacia el entorno, además el rendimiento laboral disminuye, y en consecuencia, la cantidad y calidad de trabajo realizado. Por lo tanto, el estrés relacionado con el trabajo es una de las mayores preocupaciones en el mundo laboral ya que las manifestaciones del mismo afectan el bienestar y el desempeño de los profesionales. Entre las consecuencias más significativas del estrés laboral se encuentra el burnout o Síndrome de Agotamiento Profesional.

Maslach considera el burnout como una combinación de agotamiento emocional, despersonalización y falta de realización personal (Guillén, 2000). El agotamiento emocional se ha definido como desgaste y pérdida de energía, la despersonalización se refiere a un cambio negativo en las actitudes hacia las personas y 
la falta de realización personal hace hincapié en la pérdida de la motivación hacia el trabajo y baja autoestima (Albaladejo et al., 2004).

Asimismo, este síndrome afecta más a aquellas profesiones que requieren de un contacto directo con las personas y que necesitan altas dosis de entrega e implicación (Albaladejo et al., 2004). El personal de salud se relaciona directamente con la enfermedad, el sufrimiento y otros factores que tienen repercusiones específicas en la vida de una persona, es por esta razón que constantemente se ven expuestos a estresores que pueden desencadenar el síndrome (Martín, Hernández, Arnillas y García, 2009).

Adicionalmente, las condiciones de trabajo que rodean al personal de salud pueden ser muy dispares si se desempeñan en instituciones de salud públicas o en instituciones privadas.

Respecto a las variables asociadas al estudio del burnout, se ha identificado que pueden considerarse aspectos sociodemográficos y situacionales. El estudio de variables como el sexo y la profesión permite identificar que grupo presenta mejores herramientas de afrontamiento ante situaciones estresantes, y adicionalmente, define hacia donde iría dirigido el foco de intervención. Por otro lado, variables como el tiempo de servicio y la jornada laboral se consideran dentro del ambiente de trabajo y son factores del entorno. El estudio de estas últimas posibilita brindar un alcance de la influencia de las características del propio trabajo y se puede considerar como punto de partida para generar estrategias que construyan un entorno laboral adecuado.

Por lo expuesto, la presente investigación pretende dar respuesta a la siguiente interrogante:

¿Existirán diferencias en las dimensiones de burnout al compararlas según sexo, profesión, jornada laboral y tiempo de servicio, en profesionales de establecimientos de salud del primer nivel de atención de Lima Metropolitana?

\subsection{Justificación y relevancia}

En primer lugar, desde el punto de vista teórico, la presente investigación permitió comprobar y validar los hallazgos referidos al burnout y a su manifestación en los profesionales de la salud. 
En segundo lugar, desde el punto de vista metodológico, si bien existen estudios de burnout relacionados a la medicina, sería de gran utilidad realizar un estudio de este tipo en el Perú y adaptarlo a la realidad de los establecimientos del primer nivel de atención o policlínicos. Se ha identificado que no existen estudios sobre burnout aplicados en policlínicos por lo que se considera relevante realizar la presente investigación con el propósito de estudiar cómo se manifiesta el síndrome en un centro de salud sin internamiento y que se caracteriza por brindar atención integral ambulatoria médica.

Se plantea la investigación en profesionales de salud que se relacionan directamente con pacientes, siendo su trabajo de alta responsabilidad. Asimismo, se ha determinado que con la finalidad de ofrecer un servicio de calidad, los recursos humanos adquieren vital importancia y al mismo tiempo no existe duda de la influencia significativa de las condiciones de trabajo sobre la calidad de vida laboral y calidad en el servicio ofrecido en las organizaciones del sector salud (Camacho-Ávila, JuárezGarcía y Arias, 2010).

Por último, desde el punto de vista práctico, determinar los niveles de burnout en los profesionales de la salud permitirá proponer y desarrollar estrategias de sensibilización y promoción que se puedan generalizar al sistema de salud en el Perú para así manejar el síndrome de una manera más efectiva. Esto posibilitará pensar en un cambio de actitudes frente a situaciones laborales estresantes y demandantes, lo que a largo plazo beneficiará a los pacientes, quienes son los que finalmente reciben el servicio sanitario. Las consecuencias del síndrome son muy peligrosas para la salud individual del profesional de la salud, así como también para los pacientes que son atendidos, ya que puede afectar el nivel de servicio, y para la misma institución donde laboran estos profesionales de la salud (Llaja, Sarria y García, 2007).

El presente trabajo también contribuirá al desarrollo de futuras investigaciones que aspiran a determinar de qué forma el síndrome de burnout afecta las organizaciones y los miembros de las mismas y constituye uno de los primeros intentos por describir de qué manera se presenta el Síndrome de Burnout en profesionales de la salud que se desempeñan en Policlínicos del Perú. Tal como se menciona en líneas anteriores, si bien se ha desarrollado el tema en profesionales de la salud de otros países, resulta 
interesante y útil que se estudie el fenómeno del Burnout adecuándolo al contexto nacional.

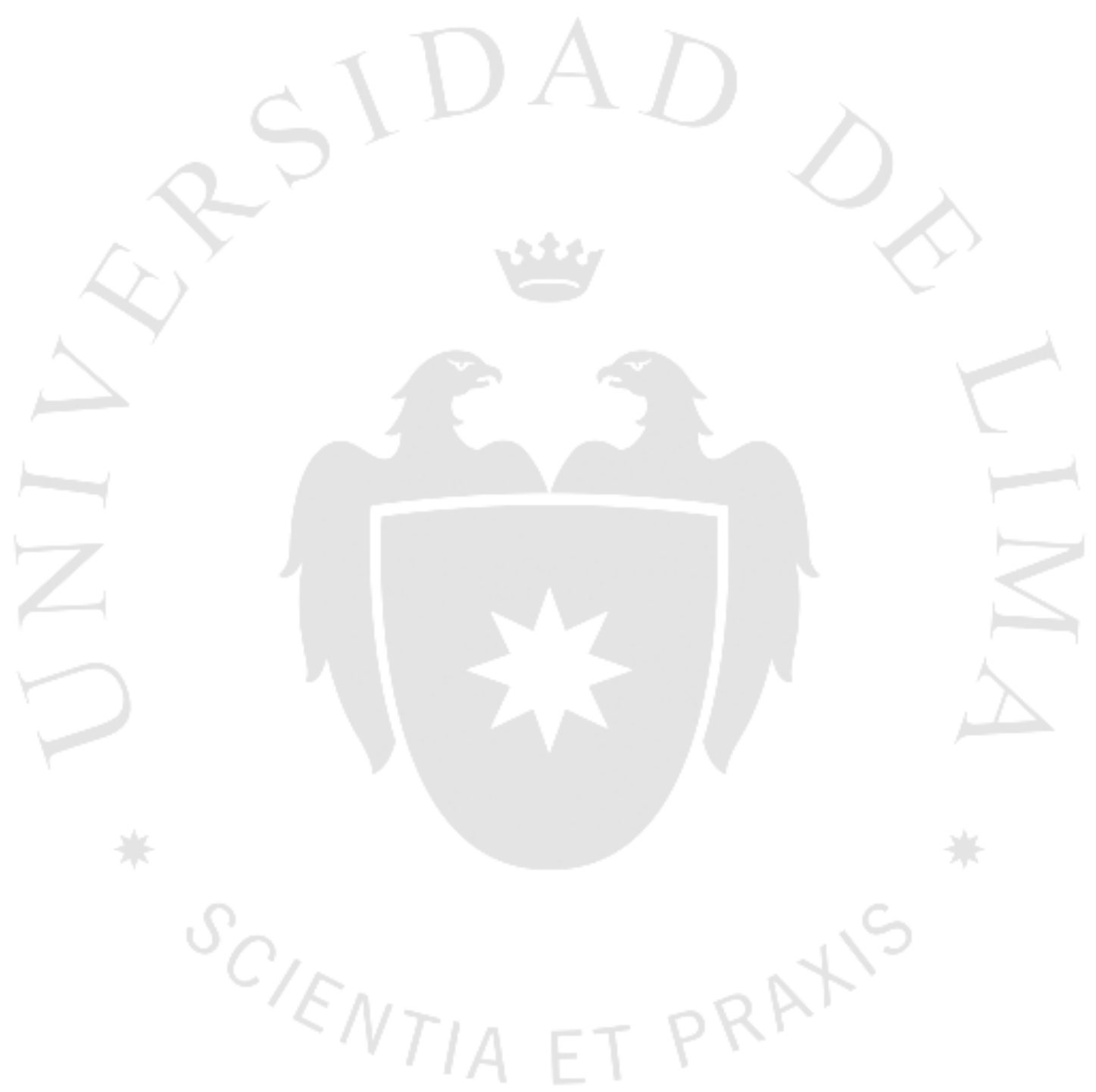




\section{CAPITULO II: MARCO TEORICO}

\subsection{Conceptualización del síndrome de burnout}

En 1974, Freudenberger definió el burnout por primera vez como "un estado particular de agotamiento físico y psicológico en los trabajadores de salud" (Fernández, 2002, p.39). Es decir, el burnout designa el proceso de deterioro en los cuidados y atención profesional a los usuarios de las organizaciones de servicios.

En un principio, el síndrome de burnout se entendía como un estado, en la actualidad se entiende más que nada como un constructo en el que se incluyen diferentes dimensiones.

Uno de los modelos de mayor aceptación que han sido utilizados para definir el síndrome es el propuesto por Maslach y Jackson, quienes entendieron el burnout como un síndrome de agotamiento emocional, despersonalización y falta de realización personal en el trabajo (Fernández, 2002, p.40).

El agotamiento emocional se da cuando la fuerza emocional se va consumiendo y el profesional ve como vacía su capacidad de entrega a los demás, tanto desde un nivel personal como psicológico. Otro aspecto del síndrome es la despersonalización que se caracteriza por la aparición de sentimientos y actitudes negativas y cínicas acerca de la persona con la que trabaja. Este proceso lleva a considerar a los profesionales que esas personas son merecedoras de sus problemas ya que se ve claramente un proceso de endurecimiento. Un tercer aspecto es la reducción de la autorrealización personal lo cual implica una tendencia a evaluarse negativamente y sentirse infeliz consigo mismo y su labor (Maslach y Jackson, 1997).

Por otro lado, según Gil Monte y Peiró (1997), el burnout es una respuesta al estrés laboral que se da de manera crónica y que aparece cuando fallan las estrategias de afrontamiento que de manera frecuente usa una persona para manejar las situaciones de estrés, y se comporta como variable mediadora entre el estrés percibido y sus consecuencias. Esta es una de las definiciones que empieza a enmarcar el síndrome 
dentro del concepto de respuesta al estrés, y que lo diferencia del estrés común ya que este último no aparece de manera crónica tal como se da en el síndrome de burnout.

Por otro lado, el síndrome de burnout puede considerarse también como "una pérdida progresiva del idealismo, de objetivos y de energía entre quienes tienen como trabajo el servicio directo a personas, secundario a dificultades laborales" (Guillén, 2000, p.276).

Como se ha visto, un elemento importante de la definición es el vínculo que la variable "burnout" mantiene con el trato directo hacia personas. Es un elemento a tomar en cuenta ya que en la presente investigación, lo que se propone es justamente describir de qué manera se presenta esta interacción en instituciones de salud pública.

Así mismo, Cherniss (1992) señala que puede existir una relación entre la poca capacidad del sujeto para desarrollar sentimientos de competencia o éxito personal y el síndrome de burnout. El concepto de autoeficacia percibida, que se refiere a la percepción que tienen las personas sobre sus capacidades para controlar las situaciones que las afectan, puede explicar la manera cómo algunas características del entorno del trabajo llevan al síndrome. De esta manera, el logro de objetivos personales incrementa los sentimientos de autoeficacia, en tanto que el no alcanzarlos puede conducir al desarrollo del síndrome.

Otras propuestas, por aclarar el concepto, intentan una clasificación del síndrome en dos categorías diferenciadas: "el burnout activo", que se demuestra por una manifestación del desgaste a través de conductas asertivas, con muestras de irritabilidad y hostilidad; y el "burnout pasivo", que viene caracterizado por las conductas de retirada y la apatía (Ponce, Bulnes, Aliaga, Atalaya y Huertas, 2005). Es así que este la manifestación del síndrome alterna entre comportamientos agresivos y conductas de alejamiento hacia las situaciones estresantes o demandantes.

\subsection{Prevalencia del síndrome de burnout}

Es de gran importancia revisar investigaciones que contengan datos vinculados a cifras de prevalencia del síndrome para así tener una noción más exacta de la frecuencia con la cual se presenta el mismo. En un estudio realizado a lo largo de distintos países de habla hispana, se encontró que la prevalencia del síndrome es mayor en España con 
un 14,9\%, mientras que en Perú por su lado, presentó una prevalencia entre 2,5\% y 5,9 \% junto a países como México, Ecuador, Colombia, Guatemala y El Salvador. Además se halló que las profesiones donde más se ve Burnout son Medicina con 12,1 \% y Enfermería con 7,2 \%. Otras como Odontología, Psicología y Nutrición tuvieron cifras inferiores al 6\% (Grau, Flichtentrei, Suñer, Prats y Braga, 2007).

Un estudio en el cual se observa la prevalencia del síndrome tuvo lugar en Cuba donde Jorge Román Hernández desarrolló en el año 2003 una investigación con 287 profesionales de la salud de un municipio de la Habana. La muestra se dividió en médicos y enfermeros de familia de consultorios comunitarios (primer nivel de atención) y del hospital general clínico-quirúrgico (segundo nivel de atención). La prevalencia del síndrome de burnout en el grupo estudiado fue ligeramente superior al $30 \%$, mientras que los síntomas de estrés se hallaron en un 50\% aproximadamente. Estos síntomas fueron los siguientes: trastornos del sueño, cefaleas, ansiedad, irritabilidad, depresión, fatiga o debilidad y acidez o ardor estomacal.

Adicionalmente, Ordenes (2004) efectuó una investigación en 250 profesionales de la salud del Hospital Roberto del Rio en Chile con la finalidad de establecer la prevalencia del síndrome de burnout. El resultado final arrojó un 31\% de síndrome de burnout, un $38 \%$ de proclividad y un $31 \%$ sin burnout.

Se pueden citar también investigaciones como la de Guntupalli \& Fromm (1996), quienes estudiaron un total de 248 Médicos a través del Inventario de Burnout de Maslach, de los que el $27.8 \%$ sólo trabajan con plena dedicación con Cuidados Intensivos. El 29\% mostró una puntuación elevada en la escala de agotamiento emocional, el $20.4 \%$ un rango alto en la despersonalización y el 59\% un rango bajo en la realización personal. La realización personal fue más elevada en aquellos profesionales que ejercían docencia.

Adicionalmente, Aranda (2006) efectuó un estudio que tuvo como objetivo el identificar las diferencias entre el ser hombre o mujer con síndrome de burnout y sus repercusiones en la salud en los médicos familiares de dos instituciones de salud en Guadalajara, México. Dentro de los hallazgos se obtuvo que la prevalencia del síndrome de burnout en la muestra fue de 41.8\%, 28 mujeres y 54 hombres. La dimensión agotamiento emocional fue la más vulnerable en ambos sexos. Según la autora, mantener un buen estado de salud y bienestar así como trabajar bajo condiciones 
seguras traerá consecuencias positivas para la institución, para el trabajador y para la población en general.

Por otro lado, Atance (1997) realizó una investigación en 294 profesionales de atención primaria y atención especializada en el área de salud de Guadalajara y dentro de sus conclusiones observó que el perfil epidemiológico de riesgo obtenido sería: mujer de más de 44 años sin pareja estable, con más de 19 años de antigüedad en la profesión y más de 11 en el centro, profesional de atención especializada, con más de 21 pacientes diarios a su cargo, a los que dedica el $70 \%$ de su jornada laboral y atiende entre 36 y 40 horas semanales.

Así mismo, es interesante conocer la perspectiva del síndrome de burnout desde el lado de las personas que aún están estudiando una carrera. En un estudio realizado en 82 estudiantes de medicina se buscó determinar la prevalencia del síndrome en alumnos de pre grado y post grado de un Hospital General, y su relación con factores psicosociales, de personalidad y variables sociodemográficas. En los resultados se obtuvo una prevalencia de 1,64\% y se encontraron niveles altos de ilusión por el trabajo, agotamiento emocional, culpa, sobreinvolucramiento (Camacho-Ávila, JuárezGarcía y Arias, 2010). De esta manera queda claro, que el síndrome está presente desde los años de estudio y no sólo cuando las personas ya son profesionales.

Una investigación comparativa que presenta características similares al tema que se va a tratar, es una que se llevó a cabo en el Instituto Mexicano del Seguro Social en Tabasco, donde se buscó determinar a través del Inventario de Maslach, la presencia del síndrome de burnout en personal médico familiar y no familiar. Los resultados reflejaron que con respecto al agotamiento emocional, los médicos familiares obtuvieron un nivel bajo, y los médicos especialistas un nivel medio. En cuanto a la despersonalización tanto los médicos familiares y especialistas obtuvieron un nivel moderado, de igual forma la falta de realización personal tuvo un nivel moderado (Borbolla-Sala y Domínguez-Sánchez, 2007).

En un estudio realizado en México cuya muestra consistió en 551 enfermeras y 71 enfermeros, se encontró que estos últimos mostraron mayor prevalencia de puntajes altos de burnout en las subescalas de Agotamiento Emocional y Reducida Realización Personal así como en la escala global. Así mismo se halló que los puntajes más altos en la escala lo obtuvieron las personas que se desempeñaban en el turno vespertino, 
seguido por el nocturno y finalmente el matutino (Martínez-López y López-Solache, 2005).

Un estudio más cercano al contexto latinoamericano, se llevó a cabo en la ciudad de Barranquilla en Colombia donde se analizó el grado de desgaste profesional en 103 enfermeras y enfermeros. Los resultados encontrados indican que existe una prevalencia baja de 1,9\% dentro de la muestra seleccionada, además en las diferentes escalas el 15, 5\% obtuvo puntuación alta para agotamiento emocional, 16,5\% para despersonalización y 9,7\% para baja realización personal (Tuesca, Iguarán, Suárez, Vargas y Vergara, 2006).

Por otro lado, en un estudio más reciente realizado en el año 2014 por Patricia Sánchez y Víctor Sierra, el objetivo fue determinar el grado de burnout en el equipo de enfermería de la UVI médica del Hospital Ramón y Cajal de Madrid. Dentro de los resultados se identificó a $45.6 \%$ de la población con tendencia a padecer burnout. "El perfil del trabajador que padece síndrome de burnout sería: enfermera, de 35 a 44 años, con contrato fijo, experiencia laboral mayor de 16 años y una antigüedad de 1 a 5 años en el puesto de trabajo" (Sánchez y Sierra, 2014, p.252). Sin embargo, Naiberg y Fenning (1991) encuentran una relación inversa debido a que los sujetos que más burnout experimentan acabarían por abandonar la profesión, por lo que los profesionales con más años en su trabajo serían los que menos burnout presentaron y por ello siguen presentes.

En relación a las investigaciones de burnout realizadas en el contexto peruano, se puede señalar que son pocos los estudios llevados a cabo en el Perú en relación al síndrome.

Fernández (2010)/resume algunas de las investigaciones realizadas en profesionales de la salud y que han tenido lugar en el contexto peruano. Según el mencionado autor, hasta el momento se han analizado 18 estudios sobre estrés, particularmente sobre el síndrome de burnout realizados con profesionales de la salud en la ciudad de Lima. Catorce estudios utilizaron un diseño descriptivo simple, dos un diseño descriptivo comparativo, y dos un diseño correlacional. En cuanto a la profesión de los autores de las investigaciones que se reportan, 9 son enfermeras, 4 son médicos, 3 son psicólogos, uno es odontólogo, y uno es médico psiquiatra. Es decir, existe una gran diferencia entre la cantidad de estudios descriptivos comparativos realizados en 
relación al número de estudios simples desarrollados, lo cual se debe tomar en cuenta al momento de realizar las investigaciones.

Los estudios se realizaron en un total de 2,242 trabajadores de Salud de Hospitales Nacionales (MINSA), de la Seguridad Social (ESSALUD) y de las Fuerzas Armadas y Policiales; en un mayor porcentaje en enfermeras, seguidas de médicos y otros profesionales. La mayoría de profesionales investigados trabajan en servicios de áreas críticas como Unidades de Cuidados Intensivos, Emergencias y Cardiología.

Como se observa, los estudios realizados en profesionales de la salud de Lima, han sido desarrollados en instituciones públicas, razón por la cual, el hecho de ampliar y tratar de generalizar estos estudios, significaría un aporte valido que complementaría la información reunida anteriormente.

En cuanto a los instrumentos utilizados, diecisiete de los estudios reportan el MBI de Maslach y uno, el test de estrés laboral de la Organización Internacional del Trabajo. Sin embargo, no reportan las propiedades psicométricas de los mismos.

Cabe resaltar que en relación a los hallazgos encontrados en las distintas investigaciones realizadas en Lima, se puede señalar que los niveles altos de burnout oscilan entre 5 y $45 \%$ (Fernández, 2010).

Entre las investigaciones que reportan hallazgos importantes respecto al tema se puede mencionar una realizada en personal sanitario de los hospitales de la empresa minera de Southern Perú Copper en el año 2005. En la población estudiada se encontró solo un médico diagnosticado con síndrome de burnout, quien se caracterizó por el desarrollo temprano del síndrome. "La baja prevalencia del burnout está asociada con las ventajas que presenta el trabajar en una compañía extranjera, con mejores niveles de ingreso, sistema privado de atención de la salud, buenas condiciones de trabajo y la participación en un permanente programa de capacitación" (Gomero, Palomino, Ruiz, y Llapyesán, 2005, p.237).

Adicionalmente, en el año 2010 un estudio buscó determinar la prevalencia y los factores asociados al síndrome de burnout en alumnos de medicina del séptimo año de la Universidad Peruana Cayetano Heredia (UPCH). La muestra estuvo constituida por 117 alumnos y se encontró una prevalencia de burnout 57.2\%. Por otro lado, se determinó que la presencia de enfermedad mental se asocia a niveles altos de 
Despersonalización y Agotamiento Emocional, mientras que la ausencia de actividades extracurriculares se asoció a elevados puntajes en Agotamiento Emocional (Estela, Jiménez, Landeo, Tomateo y Vega, 2010).

Por otro lado, en el presente año se realizó una investigación que buscó estimar la prevalencia del síndrome de burnout en el año 2014 según los diferentes puntos de corte establecidos en la literatura. Dentro de los 5062 profesionales de la salud se obtuvo una prevalencia global del síndrome de burnout de $2.8 \%$, usando valores predeterminados, $7.9 \%$ para puntos de corte según cuartiles y $12.5 \%$ usando terciles. La prevalencia fue mayor en médicos que en enfermeras independientemente del punto de corte utilizado (Marticorena, Beas, Anduaga, y Mayta, 2016).

En el año 2011 se buscó determinar la frecuencia de coexistencia de síndrome de burnout y síntomas depresivos en 84 médicos residentes del Hospital Nacional Cayetano Heredia ( $\mathrm{HNCH})$. La frecuencia de burnout identificada fue de $54.9 \%$ y de sintomatología depresiva 38.6\%. Como resultado final de la investigación se encontró que la coexistencia entre síndrome de burnout y síntomas depresivos fue de $32.9 \%$ (Mariños, Otero, Tomateo y Málaga, 2011).

De la misma manera, en el año 2014 también se realizó una investigación en el Hospital Nacional Cayetano Heredia $(\mathrm{HNCH})$. El estudio buscó determinar la frecuencia del síndrome de burnout y los niveles de sus dimensiones en los trabajadores del Servicio de Emergencia Pediátrica. Participaron 54 trabajadores entre médicos, enfermeras y técnicos de enfermería y la frecuencia del síndrome de burnout fue de $3.76 \%$. Por otro lado, la falta de trabajo de la cónyuge, sexo, condición laboral y tiempo de trabajo tuvieron una relación estadísticamente significativa con las dimensiones del burnout (Vásquez, Maruy y Verne, 2014). Por otro lado, en otra investigación realizada en el año 2008 se encontró que la Unidad de Cuidados Intensivos presenta un mayor porcentaje de burnout que el de otras especialidades. (Gamonal, García, y Silva, 2008).

Adicionalmente, el estudio de Guido (2006), realizado sólo con profesionales médicos, reporta un $33.3 \%$ de altos niveles de burnout, los mismos que están asociados con médicos de entre 27 y 40 años de edad, estado civil casado, con menos años de ejercicio profesional y con mayor número de horas laborales en salas de operaciones y en guardias a la semana. 
Asimismo, Capa (como se citó en Llaja, 2006) presenta en un estudio, con la escala MBI adaptada, y un muy buen índice de confiabilidad puesto que los índices de consistencia interna estimados mediante el alpha de Cronbach fueron altos, siendo los valores alpha .91, .92 y .86 para Agotamiento Emocional, Despersonalización y Reducida realización personal respectivamente y, los coeficientes obtenidos mediante la prueba de test - retest, también muestran valores que superan el umbral del punto de corte igual a .70, considerado como indicador de una buena confiabilidad para los instrumentos de medición psicológica.

En cuanto a los resultados finales de esta investigación, uno de los hallazgos importantes fue que en la muestra total estudiada, un gran número de profesionales presentan burnout (44.8\%) lo que llevó a afirmar que el nivel de prevalencia del síndrome de burnout en los profesionales de la salud que fueron estudiados fueron altos, ya que el instrumento es confiable y permite establecer los niveles adecuados según la muestra. Asimismo, el $16 \%$ de los profesionales presentaron algún grado de riesgo o tendencia al burnout. "Estos resultados indicaron que los profesionales más afectados por el estrés laboral asistencial son las Obstetrices y los menos afectados son los Trabajadores Sociales” (Llaja, 2006, p.119).

Por otro lado, Llaja (2006) señala que en el medio peruano, referente a estudios con Profesionales de Medicina Intensiva, sólo existe uno preliminar sobre el estrés laboral en una muestra de 60 enfermeras de las Unidades Críticas del $7^{\circ}$ B UCI y UCIN del Hospital Nacional Edgardo Rebagliati Martins, donde se concluyó que: "El $45 \%$ de los casos se encuentra en un nivel de estrés alto y el $43.3 \%$ en término medio, lo que significaba que más de la mitad del Personal de Enfermeras estaba en alto riesgo de presentar el Síndrome de UCI'(p.114).

Según Llaja (2006, p.114), "se determinó que el nivel de estrés acumulado más alto se encontraba en el personal de Enfermería de UCI 7B. Además, entre los factores facilitadores de estrés laboral, se halló un alto porcentaje en las condiciones de trabajo $(30.1 \%)$, las vivencias frecuentes ante la muerte (18.4\%), recursos inadecuados de personal (16.7\%) y falta de mecanismos compensatorios en el aspecto familiar y/o social (13.3\%)".

Por otro lado, se analizaron nueve reportes de investigaciones sobre estrés en trabajadores de salud, que laboran en Hospitales del MINSA, de ESSALUD y de una 
Compañía Minera, realizados en las ciudades de Trujillo, Cusco, Moquegua, Arequipa, Huacho, Tacna y Sullana.

Seis estudios han utilizado un diseño descriptivo simple, una investigación el diseño descriptivo comparativo y los dos restantes un diseño correlacional. Para la medición de los niveles de estrés, siete estudios utilizaron el MBI de Maslach y dos, otros instrumentos para medir factores asociados al estrés, estresores y ansiedad. Tres reportaron propiedades psicométricas adecuadas, en tanto que los seis restantes no ofrecen datos referidos a este rubro. Se ha evaluado a un total de 701 trabajadores de la salud, entre los cuales destacan enfermeras, médicos, auxiliares, técnicos, personal sanitario, practicantes de psicología y practicantes de enfermería (Fernández, 2010).

A diferencia de los estudios realizados en la capital, se puede rescatar que en provincias los niveles altos de estrés oscilan entre 0 y $15 \%$, encontrándose pues una baja prevalencia de burnout. Los bajos niveles de estrés encontrados en los estudios reportados pueden deberse a las características de las ciudades de provincias en donde no hay una vida tan agitada como en Lima, los costos de vivienda, alimentación y transporte son menores, lo cual disminuye la sensación de estrechez económica en los profesionales de la salud (Fernández, 2010). Dicho lo anterior, se puede rescatar que los estilos de vida juegan también un papel importante dentro del desarrollo del síndrome.

Entre los hallazgos encontrados en algunas investigaciones realizadas en provincias, se puede señalar una llevada a cabo por Quiroz y Saco (2003) en el Hospital Nacional Sur Este de ESSSALUD del Cuzco. En dicha investigación, los resultados señalaron que existe una asociación significativa entre burnout con género masculino, profesión médico, tiempo de servicio mayor a 12 años, baja motivación laboral y alta insatisfacción laboral.

Así mismo, existen investigaciones en otros ámbitos como el educativo. Quizá una de las más significativas es la realizada por Fernández (2008), donde se resumen tres estudios realizados en 929 profesores de escuelas primarias y secundarias de Lima. Se utilizaron diversos instrumentos para medir las variables, y en el caso del burnout se usó el Inventario de Maslach (MBI). Los resultados mostraron la existencia de un elevado nivel de burnout en los profesores, que fue más alto en los de escuela primaria que en los de secundaria. Así mismo, se encontró una relación significativa entre los 
estresores, conducta tipo A, satisfacción en el trabajo y variables de desempeño docente, tales como la auto-eficacia percibida, que puede verse como un factor protector contra el burnout.

\subsection{Signos y Síntomas}

Cuando se habla de síndrome, este constituye un conjunto de síntomas que caracteriza a una determinada condición, razón por la cual para tener una proximidad al presente tema, es necesario delimitar cuales con los síntomas y signos que caracterizan al burnout.

A diferencia de un estrés puro, el "burnout" siempre está asociado a sentimientos de desvalorización y fracaso. Según Ponce et al. (2005), el síndrome del "burnout" se manifiesta bajo unos síntomas específicos, siendo los más habituales:

- Psicosomáticos: Cansancio, fatiga crónica, frecuentes dolores de cabeza, malestar general, problemas de sueño, contracturas y algias óseo musculares, ulceras y otros desórdenes gastrointestinales, pérdida de peso, taquicardia, hipertensión, etc.

- Conductuales: Mala comunicación, ausentismo laboral, abuso de drogas (café, tabaco, alcohol, fármacos, etc.), incapacidad para vivir de forma relajada, superficialidad en el contacto con los demás, aumento de conductas violentas, trastornos en más o en menos del apetito y la ingesta, distanciamiento afectivo de los clientes y compañeros.

- Emocionales: Distanciamiento afectivo como forma de protección del yo, aburrimiento y/actitud cínica, impaciencia e irritabilidad, sentimiento de omnipotencia, desorientación, incapacidad de concentración, disminución de la memoria inmediata, baja tolerancia a la frustración, sentimientos depresivos, sentimientos de vació, agotamiento, fracaso, impotencia, baja autoestima y pobre realización personal.

- Laborales: Detrimento en la capacidad de trabajo, detrimento en la calidad de los servicios que se presta a los clientes, aumento de interacciones hostiles, comunicaciones deficientes, frecuentes conflictos interpersonales en el ámbito del trabajo y dentro de la propia familia. 
Por otro lado, continuando con Ponce et al. (2005), las evidencias que afectan al individuo en el inicio de la aparición de la enfermedad, se reconocen en varias etapas y son:

- Exceso de trabajo.

- Sobreesfuerzo que lleva a estados de ansiedad y fatiga.

- Desmoralización y pérdida de la ilusión.

- Pérdida de vocación, decepción de los valores hacia los superiores.

Asimismo, Pines y Maslach (1978) señalan que en el ambiente laboral los signos de aparición de desgaste profesional son:

- Falta de energía y entusiasmo.

- Descenso del interés por los usuarios.

- Percepción de éstos como frustrantes, crónicos y desmotivados.

- Alto absentismo y deseos de dejar el trabajo por otra ocupación.

\subsection{Estadíos}

El burnout es un síndrome que como tal, se va expresando en distintas etapas y va alcanzando su manifestación más clara a medida que se van presentando un mayor número de signos y síntomas en la persona afectada. Es por esta razón que a continuación se detallarán los estadíos del burnout tomando en cuenta primero, un enfoque lineal y a continuación un enfoque cíclico, de acuerdo a la forma como se van desarrollando las etapas.

Según Borbolla-Sala y Domínguez-Sánchez (2007), se puede estratificar el síndrome de burnout en tres estadíos:

- Primer estadío, en el que las demandas laborales exceden los recursos materiales y humanos, dándose una situación de estrés. Es decir, si existen demandas en el trabajo que sean mayores a los recursos o herramientas con las que cuenta la persona, este será el punto de partida del síndrome. Asimismo, existen una serie de factores y situaciones que conducen al estrés como el desencanto en el trabajo, exceso de compromiso, responsabilidad y enfrentamiento a situaciones difíciles, y un excesivo contacto directo con otros seres humanos. Según los autores "la 
sintomatología pasa por varias etapas; aparecen síntomas de ansiedad a nivel cognitivo-subjetivo: preocupación, temor, inseguridad, pensamientos negativos sobre sí mismos, pensamientos negativos sobre nuestra actuación ante los otros. A nivel fisiológico: tensión muscular, cefaleas. Y a nivel observable: el aumento de consumo de tabaco, alcohol, café, etc.” (Borbolla-Sala y Domínguez-Sánchez, 2007, p.578).

- Segundo estadío, hace referencia a que "en los excesos en los que el sujeto daría una respuesta emocional a ese desajuste, aparecen signos de ansiedad y fatiga; esta situación exige al sujeto una adaptación psicológica” (Borbolla-Sala y DomínguezSánchez, 2007, p.578).

- Tercer estadío, en el cual "el enfrentamiento defensivo le conduce a un cambio de actitudes frente a lo que le supone una situación laboral intolerable. Esta fase requiere que se trate al sujeto en todos sus componentes físicos y psíquicos" (Borbolla-Sala y Domínguez-Sánchez, p.578). En resumen, cuando empiezan a aparecer signos de ansiedad, el sujeto debe tratar de formular una respuesta y adaptarse a la situación estresante. Una vez instalado el síndrome se observa en las personas que lo padecen, signos tales como falta de energía y entusiasmo lo cual se traduce en una disminución del interés por los pacientes. Además, se percibe la frustración, la baja motivación, y aparecen los deseos de abandonar el trabajo, ya que se experimenta también una gran desmoralización.

Por otro lado, Edelwich y Brodsky proponen un modelo progresivo compuesto por cuatro etapas diferentes, que van de más a menos (Llaja, 2006).

- En la primera etapa de idealismo y entusiasmo, "el trabajador tiene una serie de expectativas irreales de lo que puede conseguir" (p.95).

- La segunda etapa corresponde al estancamiento, "supone una paralización tras la constatación de la irrealidad de las expectativas y una pérdida del idealismo y entusiasmo iniciales" (p.96).

- La fase siguiente, y la principal es la de frustración. La persona lleva mucho tiempo estancada y esto le produce sensación de que, a pesar de su esfuerzo, no logra lo que se propone y sus expectativas no se ven cumplidas.

- Lo anterior desemboca finalmente en la etapa de apatía caracterizada por indiferencia y falta de interés hacia las actividades que realiza, y donde a consecuencia de lo anterior se establece un sentimiento de vacío que puede 
manifestarse en forma de distanciamiento emocional y de desprecio hacia las personas con las que se trata. Esta es la etapa en la cual se manifiesta básicamente el síndrome.

Según Llaja (2006), la progresión de este modelo no es lineal, más bien, se trata de un modelo cíclico. Al decir cíclico, se refiere a que justamente este proceso se puede presentar en distintos momentos y en distintas situaciones laborales en las que se ve implicado el sujeto.

\subsection{Desencadenantes del burnout}

Existen algunos elementos que ayudan en cierta forma a que se dé la aparición y manifestación del Burnout en cada persona. Es importante tomar en cuenta a Peiró (como se citó en Guillén, 2000) quien establece cuatro categorías para el análisis de los estresores laborales:

- Ambiente físico del trabajo:

- Nivel de ruido y en concreto sus características de intensidad, control, predictibilidad y frecuencia.

- Iluminación.

- Temperatura y condiciones climáticas.

- Condiciones higiénicas y toxicidad.

- Demandas estresantes del puesto: trabajo nocturno, turnos rodados, exposición a riesgos y peligros, etc. La sobrecarga laboral percibida es un importante desencadenante del síndrome, especialmente por lo que supone de incremento de los sentimientos de agotamiento emocional.

- Desempeño de roles, relaciones interpersonales y desarrollo de la carrera:

El denominado estrés de rol está integrado básicamente por dos disfunciones de rol:

- Ambigüedad de rol: Constituye la incertidumbre del sujeto respecto al rol que desempeña y puede deberse a una falta de información del rol establecido, lo cual impide un desarrollo adecuado del mismo. 
- Conflicto de rol: Existe un conflicto entre expectativas de rol que se contradicen la una con la otra.

Tanto una como otra presentan relaciones inversas con los sentimientos de realización personal en el trabajo y relaciones directas con agotamiento emocional y la despersonalización.

Cabe considerar los efectos que tiene sobre el síndrome las relaciones interpersonales con los compañeros, supervisores, subordinados y usuarios. Leiter y Maslach (1988) señalan que las relaciones interpersonales de naturaleza formal aumentan los sentimientos de agotamiento emocional mientras que las relaciones de naturaleza informal aumentan los sentimientos de realización personal en el trabajo.

Otro grupo de factores a tener en cuenta es el desarrollo de la carrera y las posibilidades de promoción. Esto plantea que los individuos se estructuran en el logro de bienes y medios para mejorar su estatus y nivel de relaciones.

- Aspectos relacionados con las nuevas tecnologías:

Las nuevas tecnologías pueden facilitar o dificultar el desempeño de las tareas y conllevan un cambio en las habilidades que el sujeto debe poner en práctica para desempeñar el trabajo.

Según Guillén (2000):

La tecnificación en las relaciones interpersonales usuario-profesional favorece en gran medida las actitudes de despersonalización. Si las exigencias cognitivas del puesto son excesivamente altas con relación al nivel de formación de los profesionales, pueden provocar una disminución del sentimiento de realización personal y una autovaloración negativa por parte de la persona (p.282).

Es de esperar que si se opta por usar en mayor medida la tecnología, la cercanía de los vínculos entre el paciente y el profesional, se reducirá de manera significativa, lo cual producirá una actitud despersonalizada. Esto debido a que al tratarse de implementación tecnológica los procesos se vuelven automáticos y la interacción es menor.

Así mismo, el autor señala la importancia de la ética dentro de este tipo de situaciones, y considera que "problemas de carácter ético asociados con el uso reiterado 
de instrumentos pueden aumentar las sensaciones de agotamiento emocional" (Guillén, 2000, p.282).

Por otra parte, aspectos pertenecientes a las dimensiones globales de la organización, como son la centralización, la complejidad y la formalización, se manifiestan como elementos determinantes del síndrome. Se les presenta como un aspecto muy significativo el clima organizacional.

- Fuentes extraorganizacionales del estrés laboral: relaciones trabajo/familia

El ámbito familiar es el que, en términos generales, ocupa el lugar central para las personas en términos de importancia, aunque se dedique con frecuencia mayor tiempo al ámbito laboral. La familia constituye el primer contacto y el grupo primario con el cual el sujeto se identifica, por lo cual la influencia que tiene en cada profesional es de suma importancia.

Según Guillén, "en general, se ha explorado cómo determinados resultados familiares influyen sobre la calidad o insatisfacción marital y cómo determinados resultados familiares, influyen sobre el compromiso con el trabajo, la satisfacción o el estrés laboral" (p.283).

Desde otro punto de vista, existen algunas características de personalidad que se ha visto que puede llevar más fácilmente a la persona sometida a un exceso de estrés a desarrollar un burnout (Llaja, 2006), y son:

- Sensibilidad a los sentimientos y necesidades de los otros.

- Dedicación al trabajo.

- Idealismo.

- Personalidad ansiosa.

- Elevada autoexigencia.

Todas estas características tienen como resultado que el estrés que tenga que hacer frente cada individuo sea mayor, y por lo tanto los recursos con los que cuente no sean suficientes para superar la situación problemática. Como consecuencia de esto, surge el burnout. 


\subsection{Efectos del burnout y manejo del síndrome}

\subsubsection{Efectos del burnout}

Como ya es sabido, el estrés laboral y el síndrome de burnout, tienen consecuencias sobre la salud del individuo, provocando enfermedades y psicopatología. Las principales consecuencias sobre la salud son los trastornos psicosomáticos o psicofisiológicos.

Según Guillen (2000), las principales consecuencias del burnout se pueden expresar en varios grupos:

- Físicos y emocionales: Problemas de salud física (cefaleas, taquicardias y palpitaciones, dolor precordial, alteraciones gastrointestinales, hipertensión, crisis asmáticas, alergias, fatiga, dolores musculares), así como problemas psíquicos (ansiedad, depresión, insomnio) y emocionales referidos a sentimientos de inadecuación, limitación e infelicidad.

- Interpersonales: Deterioro de la vida familiar y social, y dificultades en las relaciones interpersonales.

- Actitudinales: Expresión y manifestación de actitudes negativas hacia los demás, hacia la organización y hacia sí mismo. Con sensaciones de insatisfacción laboral y reducidos niveles de compromiso e implicación.

- Conductuales: Comportamientos inadecuados relacionados con el trabajo y con la organización, presentándose conductas como agresividad, inhibición, cambios del estado de humor, etc. Así como absentismo laboral lentitud en el desempeño, disminución de la calidad y cantidad en el rendimiento laboral.

Si uno se enfoca principalmente en el ámbito organizacional, el estrés laboral también tiene consecuencias negativas, tales como la insatisfacción laboral y dificultad para establecer sistemas de motivación en el trabajo. Según Guillén (2000):

Otra consecuencia importante es el alto nivel de absentismo laboral, la tendencia a abandonar tanto el puesto de trabajo como abandonar la organización, el deterioro en la calidad del desempeño laboral, el cada vez más bajo interés por las cuestiones laborales con un tedio en aumento y la tendencia al incremento de conflictos laborales, con dificultades entre los compañeros de trabajo y con los supervisores, así como el aumento cada vez más importante de los accidentes laborales (p.286). 


\subsubsection{Manejo del síndrome de burnout}

Según Lazarus y Folkman (como se citó en Choy, 2007) el afrontamiento representa los esfuerzos cognitivos y conductuales que se desarrollan para manejar las demandas específicas, externas y/o internas, que son evaluadas como excedentes o desbordantes de los recursos que tiene la persona (p.74). Por lo tanto, el estrés resulta de la relación entre el individuo y el entorno, en la cual se tienen en cuenta las características del individuo por un lado y la naturaleza del medio por otro.

El afrontamiento es un proceso y tiene tres aspectos principales. El que hace referencia a las observaciones y valoraciones relacionadas con lo que el individuo realmente piensa o hace. El segundo aspecto refiere que lo que el individuo piensa o hacer se da en un determinado contexto. Por último, el afrontamiento es un proceso cambiante en el individuo, dado que en un momento cuenta principalmente con estrategias defensivas y en otros con aquellas que sirvan para resolver problemas, todo ello a medida que va cambiando su relación con el ambiente (Martínez et al., 2005).

Adicionalmente, según Lazarus y Folkman (1985), el modo de afrontamiento de una persona depende de factores tales como: el nivel de salud y energía física, creencias existenciales, creencias generales sobre el control y los valores y creencias culturales.

Las funciones del afrontamiento son básicamente de dos tipos (Martínez et al., 2005):

- Afrontamiento dirigido al problema: El sujeto busca cambiar la relación existente ya sea alejando o disminuyendo el impacto de la amenaza. De esta manera, las estrategias están dirigidas a la definición del problema, búsqueda de soluciones alternativas y consideración de alternativas.

- Afrontamiento dirigido a la emoción: Los esfuerzos del afrontamiento se dirigen a cambiar la manera en que se interpreta la realidad y con ellos también modificar la reacción emocional. Se incluyen estrategias tales como la minimización, el distanciamiento, la atención selectiva, las comparaciones positivas y la extracción de los aspectos positivos que averían en los hechos negativos. 
Adicionalmente, las etapas del afrontamiento son tres (Lazarus y Folkman, 1985):

- Anticipatoria o de aviso: El acontecimiento no ha ocurrido todavía y los aspectos principales a evaluar incluyen la posibilidad de que el acontecimiento ocurra o no, el momento en el que ocurrirá y la naturaleza de lo que ocurre. El proceso también valora si el individuo puede manejar la amenaza, hasta qué punto y de qué forma.

- De impacto o de confrontación: El individuo empieza a comprobar si el acontecimiento es igual o peor de lo que esperaba.

- Post-confrontación: El individuo busca como afrontar la situación tanto psicológica como materialmente.

Por otro lado, Murphy propone la existencia de distintos niveles de intervenciones que tienen distintos objetivos (Arnold y Randall, 2012):

- Primaria: Modifica el diseño, la organización y el manejo del trabajo. Es decir, se enfocan en las fuentes de estrés en el trabajo o intentan diseñar las fuentes de bienestar. Elkin y Rosch (1990) resumen una variedad de posibles estrategias dirigidas para reducir el estrés tales como rediseñar tareas, rediseñar el ambiente laboral, establecer horarios de trabajo flexibles, fomentar la administración participativa, incluir al empleado en el desarrollo de carrera, analizar los roles de trabajo y establecer metas, brindar apoyo social y retroalimentación, crear equipos cohesivos, establecer políticas justas para los empleados y establecer métodos justos para la distribución de recompensas.

- Secundaria: Tiene como objetivo modificar las respuestas psicológicas de los empleados hacia los elementos estresantes de su trabajo. Se trata de reducir o eliminar el daño que pudieran experimentar los empleados, sin alterar su exposición a las fuentes de estrés. Las intervenciones están diseñadas para ayudar a los empleados a evaluar las situaciones de una forma más positiva y por lo tanto, se requiere de habilidades especiales para impartir estas capacitaciones.

- Terciaria: Tiene como objetivo ayudar a quienes ya sufrieron algún daño a causa de su trabajo. Estas intervenciones están orientadas a rehabilitar a los empleados, por ejemplo, promoción de la salud y orientación en el centro de trabajo. 
Adicionalmente, Arnold y Randall (2012), señalan que cualquier intervención debe diseñarse a la medida del escenario organizacional en particular y de los empleados implicados. Cada organización debe seguir un enfoque sistemático de solución de problemas o de manejo de riesgo por lo que se recomienda lo siguiente:

- En primer lugar: Estar consciente y aceptar que existe un problema. Es importante que cada empleado sea capaz de reconocer su propia sintomatología del estrés y que la organización busque crear un clima de apoyo en lugar de castigarlo.

- En segundo lugar: El sujeto debe llevar un registro de experiencias e identificar los factores de estrés.

- En tercer lugar: Se debe realizar el intento de eliminar el problema o cambiarlo. $\mathrm{Si}$ el sujeto identifica el factor de estrés se puede desarrollar un plan de acción para eliminar la fuente de estrés o modificarla.

- En cuarto lugar: Si no es factible modificar el problema o factor de estrés se deben encontrar formas de afrontarlo.

- En quinto lugar: Se deben monitorear y revisar los resultados. Es decir, se debe evaluar la solución implementada con el propósito de saber si las intervenciones están teniendo el efecto deseado.

Finalmente, Keith y Newstrom (2007), señalan la importancia de la orientación que consiste en analizar el problema que se presenta para así poder ayudar al empleado a enfrentarlo mejor. Generalmente, la orientación es confidencial con la finalidad de que los trabajadores se sientan libres de hablar abiertamente sobre sus problemas laborales y personales. Asimismo, los objetivos generales de la orientación son ayudar a los empleados a aumentar la confianza en sí mismos, la comprensión, el autocontrol y la habilidad para trabajar eficazmente.

Los mismos autores también detallan que existen tres tipos de orientación:

- Orientación directiva: Es el proceso que consiste en escuchar el problema de un trabajador, decidir con él que se debe hacer y después motivarlo para que actúe.

- Orientación no directiva: Consiste en escuchar de manera activa y motivar a quien es orientado a explicar los procesos conflictivos, entenderlos e identificar las soluciones correctas. 
- Orientación participativa: Es una relación mutua entre el orientador y el trabajador en la que se establece un intercambio compartido de ideas para ayudar a resolver los problemas del orientado.

\subsection{El rol de las variables situacionales en el síndrome de burnout}

Según Maslach y Jackson (como se citó en Llaja, 2006), una de las variables situacionales que parece ser central en la aparición del estrés ocupacional, es la cantidad y calidad o grado del contacto con otras personas que son los receptores de los servicios (p. 106), que en el caso de la presente investigación son los pacientes. Es decir que cuanto más tiempo se le dedica al paciente, mayor riesgo de padecer agotamiento emocional presenta el profesional de la salud.

Estos autores han demostrado que cuanto más tiempo pasan los médicos en contacto directo con el paciente, más alta era su puntuación en la escala de agotamiento emocional. En algunos casos son los propios sentimientos y conductas de los pacientes, las causas de esa exigencia emocional. El paciente puede estar muy ansioso, o sentirse amenazado por la enfermedad, o por el tratamiento. Asimismo, puede reaccionar muy negativamente a lo que se le informa o expresar una ira injustificada (Llaja, 2006, p. 106).

Tratando de demostrar la influencia de la cantidad de horas, en la aparición del síndrome, se vio pertinente revisar la investigación de Barría (2003), quien realizó un estudio en Chile con una muestra conformada por Asistentes Sociales del Servicio Nacional de Menores de la Región Metropolitana y encontró que una jornada de trabajo de más de 8 horas en el mismo lugar, incrementa la probabilidad de aparición del burnout. Adicionalmente, otra investigación realizada en 143 médicos residentes del Instituto Mexicano del Seguro Social concluyó que existe relación entre la presencia del síndrome de desgaste profesional y trabajar jornadas mayores o iguales a 80 horas por semana (López, González, Morales y Espinoza, 2006).

Una segunda fuente, lo constituye la naturaleza de la enfermedad que se está tratando. Algunas enfermedades pueden ser muy estresantes para el propio profesional, 
ya sea por la naturaleza de los síntomas, o por la gravedad de su pronóstico (Llaja, 2006).

Una tercera fuente, se da como resultado de los problemas de comunicación con los pacientes. El personal de salud tiene en muchas ocasiones dificultades para comunicarse directamente con ellos. Una situación especial es la del enfermo internado en una UCI, la condición comatosa o de paciente crítico hace imposible la comunicación con él (Llaja, 2006, p. 107). Si esta situación se mantiene durante mucho tiempo, existe la posibilidad de que se establezca una relación cada vez más despersonalizada entre el profesional y el paciente, ya que no existe manera de entablar contacto verbal con él.

Por otro lado, el profesional puede desarrollar una percepción negativa del paciente y sus esfuerzos pueden dejar de tener un efecto significativo sobre la vida y condición de la persona enferma. Esto trae como consecuencia que el profesional genera sentimientos de fracaso e ineficacia, lo que termina muchas veces en una baja calidad de la asistencia (Llaja, 2006).

Otra de las fuentes de tensión emocional es la necesidad de tratar con los familiares del paciente. Muchas veces, los familiares no entienden la real situación del paciente, y creen que los profesionales tienen a la mano las herramientas suficientes para salvarlo, lo cual en ocasiones no es así y esto determina que se desarrollen sentimientos negativos en la relación familia-profesional.

Otro aspecto clave situacional en la aparición de estrés ocupacional es la frustración relativa, que puede ser muy alta. Se trata de la diferencia entre las expectativas de éxito y el éxito conseguido. Los sentimientos de frustración, resultan de la combinación de continuos fracasos y expectativas no muy realistas. Incluso cuando los profesionales llevan más años trabajando y se han ajustado mejor las expectativas, siguen persistiendo expectativas que son centrales a las profesiones de salud, tales como: curar al paciente, salvar su vida, devolverle la salud. Por ello, en aquellos servicios, en las que tales metas son prácticamente imposibles, los niveles de estrés son especialmente altos (Llaja, 2006).

Adicionalmente, es de gran relevancia vincular el síndrome de burnout con el aspecto social, y revisar investigaciones que efectivamente involucran factores de este 
tipo. En México se llevó a cabo una investigación que tuvo como objetivo determinar si la presencia de factores psicosociales negativos estaba relacionada con el desarrollo del síndrome de burnout. Entre los resultados más sobresalientes se encontró una prevalencia de $42,3 \%$ de médicos con burnout. Adicionalmente, el ser soltero, tener estudios superiores o inferiores al puesto, y contar con factores psicosociales negativos fueron considerados elementos de riesgo para el desarrollo del síndrome (Aranda, Pando, Salazar, Torres, Aldrete y Pérez, 2004).

Vinculado a la investigación anterior, se llevó a cabo un estudio cuyo objetivo fue valorar el nivel de burnout y estudiar las variables sociodemográficas y laborales que pueden influir sobre éste, teniendo en cuenta una muestra que se componía de 55 especialistas de urgencias, psiquiatría y UCI. Los resultados arrojaron que un factor protector contra el síndrome es la percepción de apoyo por parte de los compañeros, además no se observaron diferencias entre los servicios y se halló también que el reconocimiento social y empresarial del trabajo disminuye el desgaste profesional y la probabilidad de sufrir un síndrome de burnout (Martín et al., 2009). Así como se ha revisado la manifestación del síndrome de burnout en médicos, es de gran relevancia para la investigación, conocer cómo se expresa el desgaste en enfermeras, ya que estas últimas son parte de la muestra del presente trabajo.

Por otro lado, según Gil Monte y Peiró (1997), el conflicto de rol se ha revelado igualmente como uno de los factores de estrés ocupacional más significativo, sobre todo en el personal de enfermería, ya que debido a este elemento, las personas que trabajan a este nivel no saben de qué manera se desempeñarán y esto puede traer consigo un desempeño bajo, lo que posteriormente, genera estrés.

El clima laboral dentro de una organización también está vinculado al síndrome de burnout, como se puede constatar en una investigación realizada en el año 2015 por Vizcarra, Llaja, Limo y Talavera. En el mencionado estudio se buscó relacionar el clima laboral con el síndrome de burnout y el perfil de personalidad frecuente en las áreas de trabajo neuroquirúrgicas. Se evaluó a 30 profesionales de la salud utilizando la escala estandarizada de Clima Laboral, Scanning Neuropsicológico y el Inventario de Burnout en la versión adaptada por Llaja. Los resultados determinaron que un $80 \%$ de la muestra no presentaba el síndrome de burnout, mientras que un $10 \%$ se encontraba con tendencia a presentarlo y un $10 \%$ en riesgo. Una de las principales conclusiones del 
estudio es que existe una correlación positiva estadísticamente entre clima laboral y burnout.

Sin embargo, en una investigación realizada en el año 2004 en 93 profesionales de la salud de centros hospitalarios públicos entre médicos, enfermeras, obstetrices, psicólogos, trabajadores sociales y tecnólogos médicos, se encontró que no existe una correlación significativa entre las escalas de estrés laboral y la escala de clima laboral en la muestra estudiada. No obstante, al interior de cada escala si existen correlaciones significativas. Asimismo, no se observan diferencias significativas en ambas variables en función al género. Adicionalmente, según la investigación, los médicos, enfermeras y tecnólogos médicos son los que presentan una mayor disposición al burnout y en lo que respecta al tiempo de servicio, en los profesionales con un tiempo de servicio entre 25 y 32 años, los niveles de estrés laboral experimentados son mayores (Bulnes, 2004).

\subsection{Establecimientos de Salud}

\subsubsection{Conceptualización y tipos de Establecimientos de Salud}

Según la Resolución Ministerial promulgada por el Ministerio de Salud del Perú (MINSA, 2011) los establecimientos de salud son aquellos que "realizan atención de salud en régimen ambulatorio o de internamiento, con fines de prevención, promoción, diagnóstico, tratamiento y rehabilitación, para mantener o restablecer el estado de salud de las personas" (p.6).

Asimismo, cada establecimiento está implementado con recursos humanos, materiales y equipos, y realiza actividades de promoción de la salud, prevención de riesgos y control de daños a la salud, asistenciales y de gestión para brindar atenciones de salud que envuelven a la comunidad, incluyendo la persona y la familia.

Según el MINSA (2011), los establecimientos de salud se clasifican de acuerdo al tipo de prestación que brindan en:

a. Establecimientos de salud sin internamiento: Son aquellos donde atienden uno o más profesionales de la salud que desarrollan actividades que se enfocan en atención clínica ambulatoria, o efectúan procedimientos diagnósticos, terapéuticos o de rehabilitación que no requieran que la persona permanezca en la institución. 
b. Establecimientos de salud con internamiento: Aquellos que brindan atención integral o especializada al usuario, y que para realizar atenciones o procedimientos clínicos o quirúrgicos, con fines diagnósticos, terapéuticos o de rehabilitación, requiera que la persona permanezca en la institución y que se le brinde un soporte asistencial por más de doce horas según el riesgo que presente.

Por otro lado, en el año 2004, la Resolución 769-2004 del Ministerio de Salud estableció unas categorías que buscan ser una primera etapa de organización de los establecimientos de salud del sector. Asimismo, el MINSA define "Categoría" como "tipo de establecimientos de salud que comparten funciones, características y niveles de complejidad comunes, las cuales responden a realidades socio-sanitarias similares y están diseñadas para enfrentar demandas equivalentes"(p.10).

Entre los elementos constitutivos a tomar en cuenta están:

1. Tamaño: Cantidad de recursos humanos, equipamiento, infraestructura, insumos, entre otros.

2. Nivel tecnológico: Especialización y tecnificación de sus recursos (humanos, equipamiento, infraestructura, insumos, entre otros).

3. Capacidad resolutiva cuantitativa: Uno de los aspectos a medir es el volumen de producción en cuanto a consultas, atención de hospitalización, atención de emergencias, intervenciones quirúrgicas, exámenes, entre otros.

4. Capacidad resolutiva cualitativa: Satisfacción de las necesidades de la demanda y capacidad de referir pacientes según diagnóstico.

\subsubsection{Tipos de Niveles de Atención}

Es de gran relevancia determinar a continuación, en qué consiste la división de niveles de atención con la finalidad de enmarcar dentro de cuál de estos se ubica el tipo de institución en que se enfocará la investigación. La Resolución Ministerial del MINSA (2011) reconoce tres niveles:

a. Primer Nivel de Atención: En este tipo de instituciones se realizan principalmente actividades de promoción de la salud, prevención de riesgos y control de daños a la salud, diagnóstico precoz y tratamiento oportuno, teniendo como eje de intervención las necesidades de salud más frecuentes de la persona, familia y comunidad. 
b. Segundo Nivel de Atención: En este nivel se agrega un grado de mayor especialización tanto en recursos humanos como tecnológicos, brindando un conjunto de servicios de salud dirigidos a solucionar los problemas de las personas referidas del primer nivel de atención o aquellas que por urgencia acudan a los establecimientos de salud de este nivel. Asimismo, se efectúan actividades preventivas o promocionales de acuerdo al caso.

c. Tercer Nivel de Atención: Es el nivel de mayor especialización y capacidad en cuanto a recursos humanos y tecnológicos dirigidos a la solución de las necesidades de salud que son referidas de los niveles de atención precedentes, así como aquellas personas que acudan a los establecimientos de este nivel por razones de urgencia. De manera similar al nivel anterior, también se efectúan actividades de prevención y promoción.

Es así que las categorías de establecimientos de salud por niveles de atención, consideradas en la presente norma $\mathrm{N}^{\circ} 546$ - 2011/MINSA son las siguientes:

Tabla 1

Categorías de establecimientos de salud por niveles de atención

\begin{tabular}{ll}
\hline Nivel de atención & Categoría \\
\hline Primer nivel de atención & Categoría I-1 \\
& Categoría I-2 \\
& Categoría I-3 \\
& Categoría I-4
\end{tabular}

Segundo nivel de atención

Establecimiento de salud de

Categoría II-1

atención general

Establecimiento de salud de

Categoría II-2

Categoría II-E atención especializada

Tercer nivel de atención

Establecimiento de salud de

Categoría III-1

atención general

Establecimiento de salud de

Categoría III-E

atención especializada

Categoría III-2

Fuente: Resolución Ministerial 546-2011-MINSA 
A continuación se presenta una tabla con el detalle del tipo de institución que se encuentra dentro de cada categoría.

Tabla 2

Denominación de establecimientos de salud según categoría

\begin{tabular}{|c|c|c|}
\hline Establecimiento de Salud & Denominación & Categoría \\
\hline \multicolumn{3}{|l|}{ Sin Internamiento } \\
\hline & $\begin{array}{l}\text { Consultorio de profesionales de } \\
\text { la salud (no Médico Cirujano) }\end{array}$ & $\mathrm{I}-1$ \\
\hline & $\begin{array}{l}\text { Puesto de salud o Posta de } \\
\text { salud (con profesional de la } \\
\text { salud no Médico Cirujano) } \\
\text { Consultorio Médico (con } \\
\text { Médico Cirujano con o sin } \\
\text { especialidad) } \\
\text { Puesto de salud o Posta de } \\
\text { salud (con Médico Cirujano) }\end{array}$ & I-2 \\
\hline & Centro de Salud & $\mathrm{I}-3$ \\
\hline & Centro Médico & \\
\hline & Centro Médico Especializado & \\
\hline & Centro Odontológico & \\
\hline \multirow[t]{12}{*}{ Con Internamiento } & $\begin{array}{c}\text { Centro de Salud con camas de } \\
\text { internamiento }\end{array}$ & $\mathrm{I}-4$ \\
\hline & $\begin{array}{l}\text { Centro médico con camas de } \\
\text { internamiento }\end{array}$ & \\
\hline & Hospital de atención general & II-1 \\
\hline & Clínica de atención general & \\
\hline & Hospital de atención general & II-2 \\
\hline & Clínica de atención general & $\frac{1}{4}$ \\
\hline & $\begin{array}{l}\text { Hospital de atención } \\
\text { especializada } \\
\text { Clínica de atención } \\
\text { especializada }\end{array}$ & II-E \\
\hline & Hospital de atención general & III-1 \\
\hline & Clínica de atención general & \\
\hline & $\begin{array}{l}\text { Hospital de atención } \\
\text { especializada }\end{array}$ & III-E \\
\hline & $\begin{array}{l}\text { Clínica de atención } \\
\text { especializada }\end{array}$ & \\
\hline & $\begin{array}{l}\text { Instituto de Salud } \\
\text { Especializado }\end{array}$ & III-2 \\
\hline
\end{tabular}

Fuente: Resolución Ministerial 546-2011-MINSA 
En base a estos elementos y a las características específicas de cada institución se han logrado establecer las distintas categorías de los establecimientos de salud a nivel nacional.

Tabla 3

Categorías de establecimientos de salud a nivel nacional

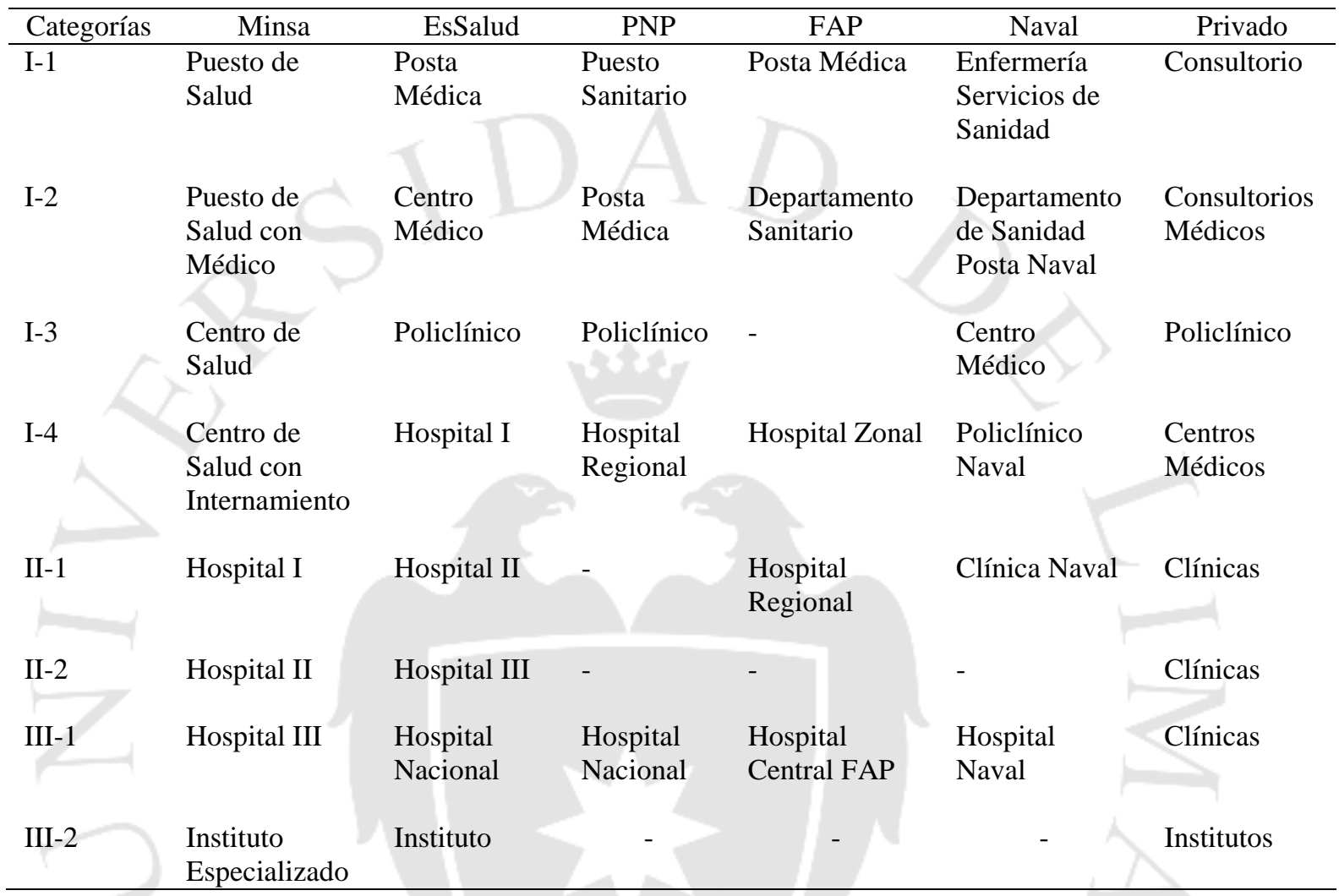

Fuente: Resolución Ministerial 769-2004-MINSA

De acuerdo al MINSA, dentro de los Establecimientos de Salud de Primer Nivel de Atención existen cuatro niveles de complejidad. En consecuencia, las instituciones que se están tomando en cuenta para la presente investigación son los Policlínicos de ESSALUD que se encuentran en la categoría I-3 según detalla la tabla.

\subsubsection{Policlínicos}

Tal como se menciona en líneas anteriores las sedes que se están tomando en cuenta para la presente investigación, es decir, los Policlínicos, pertenecen a la categoría I-3. Según el MINSA (2004) los establecimientos de salud del primer nivel de atención que se encuentran dentro de la categoría I-3 se caracterizan por brindar atención integral ambulatoria médica con énfasis de promoción en riesgos y daños. 
Asimismo se trata de centros de salud sin internamiento y que tienen como principales funciones la promoción, prevención, recuperación y rehabilitación.

Según la Resolución Ministerial 546-2011 la Categoría I-3 es definida como un “ grupo de clasificación de un establecimiento de salud del primer nivel de atención con capacidad resolutiva para satisfacer las necesidades de salud de la persona, familia y comunidad, en régimen ambulatorio, mediante acciones intramurales y extramurales y a través de estrategias de promoción de la salud, prevención de riesgos y control de daños a la salud, así como las de recuperación y rehabilitación de problemas de salud..." (p.23).

Como se ha observado en la tabla, corresponden a esta categoría los siguientes establecimientos de salud:

- Centro de Salud.

- Centro Médico.

- Centro Médico especializado.

- Policlínico

Los establecimientos de salud con población asignada cuentan como mínimo con dos o más Médicos-Cirujanos. Asimismo, cuentan con profesionales: de Odontología, de Enfermería, de Obstetricia; y personal técnico de enfermería, de laboratorio y de farmacia.

Por otro lado, "en estos establecimientos de salud debe desarrollarse la actividad de Salud Familiar y Comunitaria, a cargo del Equipo Básico de Salud Familiar y Comunitaria constituido por profesionales de Medicina Humana, Enfermería, y Obstetricia; y personal técnico(a) de enfermería con competencias en salud familiar y comunitaria, y realizan preferentemente actividades de atención ambulatoria extramural" (MINSA, 2011, p.23).

Los establecimientos de salud sin población asignada deben contar como mínimo con dos o más Médicos-Cirujanos con o sin especialidad, con personal técnico de enfermería y de Laboratorio. Opcionalmente tienen otros profesionales de la salud de acuerdo a las necesidades de salud existentes y número de pacientes. 


\section{CAPITULO III: OBJETIVOS}

\subsection{Objetivos}

- Describir los niveles de burnout en profesionales de establecimientos de salud del primer nivel de atención de Lima Metropolitana.

- Describir los niveles de burnout según el sexo en profesionales de establecimientos de salud del primer nivel de atención de Lima Metropolitana.

- Describir los niveles de burnout según la profesión en profesionales de establecimientos de salud del primer nivel de atención de Lima Metropolitana.

- Describir los niveles de burnout según la jornada laboral en profesionales de establecimientos de salud del primer nivel de atención de Lima Metropolitana.

- Describir los niveles de burnout según el tiempo de servicio en profesionales de establecimientos de salud del primer nivel de atención de Lima Metropolitana.

- Comparar la cantidad de agotamiento emocional, despersonalización y reducida realización personal según el sexo en profesionales de establecimientos de salud del primer nivel de atención de Lima Metropolitana.

- Comparar la cantidad de agotamiento emocional, despersonalización y reducida realización personal según la profesión en profesionales de establecimientos de salud del primer nivel de atención de Lima Metropolitana.

- Comparar la cantidad de agotamiento emocional, despersonalización y reducida realización personal según la jornada laboral en profesionales de establecimientos de salud del primer nivel de atención de Lima Metropolitana.

- Comparar la cantidad de agotamiento emocional, despersonalización y reducida realización personal según el tiempo de servicio en profesionales de establecimientos de salud del primer nivel de atención de Lima Metropolitana.

\subsection{Hipótesis}

- Existen diferencias estadísticamente significativas entre las dimensiones de agotamiento emocional, despersonalización y reducida realización personal según el 
sexo en profesionales de establecimientos de salud del primer nivel de atención de Lima Metropolitana.

- Existen diferencias estadísticamente significativas entre las dimensiones de agotamiento emocional, despersonalización y reducida realización personal según la profesión en profesionales de establecimientos de salud del primer nivel de atención de Lima Metropolitana.

- Existen diferencias estadísticamente significativas entre las dimensiones de agotamiento emocional, despersonalización y reducida realización personal según la jornada laboral en profesionales de establecimientos de salud del primer nivel de atención de Lima Metropolitana.

- Existen diferencias estadísticamente significativas entre las dimensiones de agotamiento emocional, despersonalización y reducida realización personal según el tiempo de servicio en profesionales de establecimientos de salud del primer nivel de atención de Lima Metropolitana.

\subsection{Definición de variables}

A continuación se detallarán algunas definiciones conceptuales y operacionales que servirán para delimitar de una manera más completa al fenómeno que se desea estudiar.

En cuanto a la definición conceptual, el síndrome de burnout es definido por Maslach y Jackson como "un síndrome de agotamiento emocional, despersonalización y falta de realización personal en el trabajo" (Fernández, 2002, p.40).

Según lo señalado, uno de los componentes del síndrome es el agotamiento emocional, el cual se da cuando la fuerza emocional se va consumiendo y el profesional ve como vacía su capacidad de entrega a los demás, tanto desde un nivel personal como psicológico (Maslach y Jackson, 1997). Otro aspecto del síndrome es la despersonalización que se define como una respuesta impersonal y fría del profesional hacia los receptores de su servicio o cuidado (Llaja, Sarria y García, 2007). Un tercer aspecto es la reducción de la autorrealización personal lo cual implica una tendencia a 
evaluarse negativamente y sentirse infeliz consigo mismo y su labor (Maslach y Jackson, 1997).

Respecto a la definición operacional, el síndrome de burnout hace referencia a los puntajes que se derivan de las respuestas de los encuestados en el Inventario de Burnout de Maslach (MBI) en función a las actitudes y sentimientos personales hacia su actividad laboral, las mismas que son medidas según las áreas de cansancio emocional, despersonalización y realización personal, lo que dará lugar a la clasificación de riesgo, tendencia o presencia del síndrome según fluctúen los puntajes en dichas áreas. 


\section{CAPITULO IV: METODOLOGIA}

\subsection{Tipo de estudio y diseño de investigación}

El presente estudio tiene un enfoque cuantitativo y un alcance de tipo descriptivo comparativo, ya que busca medir y recoger información acerca de las propiedades, características y rasgos importantes del Burnout en profesionales de Establecimientos de Salud del Primer Nivel de Atención de Lima Metropolitana. Además, pretende describir las tendencias de cada grupo o población con la finalidad de efectuar comparaciones. Asimismo, se utiliza un diseño de investigación no experimental transversal dado que se desea describir cómo se manifiesta actualmente el Síndrome de Burnout en la muestra seleccionada (Hernández, Fernández y Baptista, 2014).

\subsection{Participantes}

La población está constituida por profesionales de la salud de 10 establecimientos del Primer Nivel de Atención de Lima Metropolitana. A nivel nacional, ESSALUD (2016) reporta que en el año 2015 la cantidad de personal asistencial fue de 44,763 personas mientras que la cantidad de personal administrativo ascendía a 9,120. Sin embargo, no se han podido obtener datos precisos acerca de la cantidad de profesionales de la salud que pertenece a los policlínicos de Lima Metropolitana.

Asimismo, la muestra o subgrupo de la población estudiada fue no probabilística de tipo por conveniencia (Hernández, Fernández y Baptista, 2014), ya que se utilizaron casos disponibles a los cuales se tuvo acceso. 
Por otro lado, la cantidad de personas que formaron parte de la muestra se calculó utilizando el programa G*Power 3 (Faul, Erdfelder, Lang y Buchner, 2007).

El tamaño del efecto (ES) obtenido de un estudio piloto de médicos y enfermeras (Quesada y Figuerola, 2010) fue de $r=.25$, considerado como mediano usando los criterios de Cohen (1988). Con un alfa $=.05$ y potencia $=.80$ (Quezada, 2007), el tamaño de la muestra proyectada necesaria con este tamaño del efecto es aproximadamente $\mathrm{N}=120$ para el desarrollo del estudio descriptivo. Por lo tanto, la propuesta de tamaño de muestra de 130 será más que suficiente para el objetivo principal de este estudio y también debe permitir una deserción esperada y cumplir con los objetivos del estudio.

Sin embargo, cabe mencionar que durante el proceso de recolección de datos se identificaron cuestionarios que no fueron completados según las indicaciones brindadas al momento de la explicación por parte del evaluador. Como consecuencia de lo mencionado, la muestra final estuvo conformada por 126 profesionales de la salud.

A continuación, en la tabla 4 se observa que la composición de la muestra por edades, osciló entre los 20 y 70 años, en el cual el mayor número de profesionales se encuentra entre los 36 y 50 años.

También se observó, que el $37.3 \%$ de la muestra correspondía al género masculino mientras que el $62.7 \%$ al femenino.

El $21.4 \%$ de la muestra reportó ser soltero, el $67.5 \%$ casado, el $1.6 \%$ viudo, el $4.0 \%$ divorciado, el $3.2 \%$ separado y el $2.4 \%$ se ubicó en la categoría de conviviente.

A su vez, en relación al lugar de procedencia, la composición de la muestra presentaba un $54.8 \%$ provenientes de Lima, un $42.1 \%$ de provincia y un $3.2 \%$ de otros lugares.

Asimismo, se observó que el $67.5 \%$ de la muestra representaba a los médicos y el otro $32.5 \%$ a las enfermeras/os.

También se estimó el tiempo de servicio de los profesionales de la salud, en donde la mayor parte de la muestra se encontraba entre los 1 a 20 años de servicio (80.2\% de la muestra). 
Tabla 4

Composición de la muestra

\begin{tabular}{|c|c|c|}
\hline Variable & Frecuencia & Porcentaje \\
\hline \multicolumn{3}{|l|}{ Edad (rango) } \\
\hline $20-35$ & 19 & $15.1 \%$ \\
\hline $36-50$ & 69 & $54.8 \%$ \\
\hline $51-70$ & 38 & $30.2 \%$ \\
\hline \multicolumn{3}{|l|}{ Género } \\
\hline Masculino & 47 & $37.3 \%$ \\
\hline Femenino & 79 & $62.7 \%$ \\
\hline \multicolumn{3}{|l|}{ Estado Civil } \\
\hline Soltero & 27 & $21.4 \%$ \\
\hline Casado & 85 & $67.5 \%$ \\
\hline Viudo & 2 & $1.6 \%$ \\
\hline Divorciado & 5 & $4.0 \%$ \\
\hline Separado & 4 & $3.2 \%$ \\
\hline Conviviente & 3 & $2.4 \%$ \\
\hline \multicolumn{3}{|l|}{ Lugar de procedencia } \\
\hline Lima & 69 & $54.8 \%$ \\
\hline Provincia & 53 & $42.1 \%$ \\
\hline Otros & 4 & $3.2 \%$ \\
\hline \multicolumn{3}{|l|}{ Profesión } \\
\hline Medicina & 85 & $67.5 \%$ \\
\hline Enfermería & 41 & $32.5 \%$ \\
\hline \multicolumn{3}{|l|}{ Tiempo de servicio } \\
\hline $1-20$ & 101 & $80.2 \%$ \\
\hline $21-40$ & 25 & $19.8 \%$ \\
\hline \multicolumn{3}{|l|}{ Jornada laboral } \\
\hline $1-18$ & 9 & $7.1 \%$ \\
\hline $19-36$ & 49 & $38.9 \%$ \\
\hline $37-54$ & 44 & $34.9 \%$ \\
\hline Más de 54 & 24 & $19.0 \%$ \\
\hline \multicolumn{3}{|l|}{ Sede } \\
\hline Policlínico A & 17 & $13.5 \%$ \\
\hline Policlínico B & 41 & $32.5 \%$ \\
\hline Policlínico C & 52 & $41.3 \%$ \\
\hline Policlínico D & 16 & $12.7 \%$ \\
\hline \multicolumn{3}{|l|}{ Trabaja en otra institución } \\
\hline Sí & 41 & $32.5 \%$ \\
\hline No & 85 & $67.5 \%$ \\
\hline Total & 126 & $100 \%$ \\
\hline
\end{tabular}


El 7.1\% de la muestra reportó trabajar entre 1 y 18 horas a la semana, el 38.9\% entre 19 y 36 horas a la semana, el $34.9 \%$ entre 37 y 54 horas a la semana, y el $19.0 \%$ indicó trabajar más de 54 horas a la semana.

Se observa también la composición de la muestra por sede de procedencia; en donde el $13.5 \%$ de la muestra corresponde al Policlínico A, el 32.5\% al Policlínico B, el 41.3\% al Policlínico C y el $12.7 \%$ al Policlínico D.

Dentro de la muestra se consideró también la actividad de los profesionales en otra institución, dentro de la cual el $32.5 \%$ trabajaba en otra institución y el $67.5 \%$ solo se empleaba en las instituciones investigadas en el presente trabajo.

\subsection{Técnicas de recolección de información}

\subsubsection{Descripción del Instrumento}

La presente investigación utilizará como instrumento la versión adaptada al Perú del Inventario de Burnout original de Maslach y Jackson, realizada por Llaja, Sarria y García (2007). A continuación, se presentará una descripción de dicho instrumento.

El instrumento que se empleará está constituido por 22 ítems que se valoran con una escala tipo Likert de siete puntos y se caracteriza por asumir que el desgaste psíquico es considerado como un síndrome caracterizado por sentimientos de agotamiento emocional, despersonalización y baja realización personal en el trabajo (Fernández, 2002).

Maslach y Jackson (1997) describen en su instrumento, qué elementos contiene cada una de las áreas mencionadas:

a) Agotamiento Emocional: Sus elementos describen los sentimientos de una persona emocionalmente exhausta por el propio trabajo.

b) Despersonalización: Los elementos de esta escala describen una respuesta impersonal y fría hacia los receptores de los servicios o cuidados del profesional. Tanto en ésta como en la escala anterior, los profesionales con puntuaciones altas presentan grados elevados de vivencia del síndrome del estrés laboral asistencial. 
c) Realización Personal: Esta escala contiene elementos que describen sentimientos de competencia y éxito en el trabajo propio con personas. En contraste con las otras escalas, las puntuaciones bajas son indicativas del síndrome, pero es independiente de ellas y sus elementos no tienen pesos negativos en ellas.

Tabla 5

Composición de las áreas del Inventario de Burnout de Maslach

\begin{tabular}{lc}
\hline Áreas & Ítems \\
\hline Agotamiento Emocional & $1,2,3,6,8,13,14,16,20$ \\
Despersonalización & $5,10,11,15,22$ \\
Baja realización personal & $4,7,9,12,17,18,19,21$ \\
\hline Total & 22 \\
\hline
\end{tabular}

La adaptación realizada por Llaja, Sarria y García (2007) se efectuó con el propósito de evaluar la incidencia de Burnout en la población peruana.

Los autores procedieron a adaptar el Inventario de Maslach y Jackson, por lo cual fue sometido al criterio de 15 jueces expertos en Psicología Clinica y de la Salud para adaptar la estructura y el contenido de los ítems. Para ello se realizó el análisis de tipo cualitativo de los ítems del Inventario, donde se clasificó los comentarios y apreciaciones de cada uno de los jueces, en categorías, que fueron seleccionadas de manera inductiva a partir de las similitudes y coincidencias de sentido del material de análisis.

Las observaciones que se hicieron al instrumento consistieron en mejorar la semántica de los ítems y reajustar la escala de frecuencia de los sentimientos. En general los jueces hicieron pocas observaciones en este inventario. Si bien las frases permanecieron en su mayoría, muy similares a la versión española original, se realizó una única modificación. En el ítem 8 de la versión española dice "Me siento Quemado por mi trabajo", y en la versión adaptada se modificó a "Me siento exhausto por mi trabajo" (Llaja, Sarria y García, 2007).

Asimismo, en la presente investigación, el enfoque que se utilizará para describir la presencia de burnout, es construir un algoritmo, basado en los puntajes de los síntomas clínicos y su temporalidad de aparición. Se puede identificar a los sujetos 
con burnout a partir de la cuantificación de los puntajes obtenidos por Escalas, y luego se los ubica dentro de las categorías: Alto, Medio o Bajo.

Según Llaja, Sarria y García (2007), se ve por conveniente crear niveles adicionales, dado que la experiencia del burnout puede ser entendida como una variable continua, de niveles crecientes. "En un momento se inicia con un solo síntoma que hablaría de Riesgo, si sigue avanzado el síndrome se incrementaría a 2 síntomas presentes: que significaría Tendencia, y finalmente la aparición de los 3 síntomas del burnout: Cansancio emocional alto, Despersonalización alta y baja Realización personal"' (p. 58).

Simplificando la creación del algoritmo y tomando como referencia los siguientes valores: Alto (3), Medio (2) y Bajo (1), se elaboró el siguiente algoritmo computacional en base a la categorización de los puntajes $\mathrm{T}$, en la siguiente nomenclatura (Llaja, Sarria y García, 2007).

- Riesgo:

Agotamiento Emocional=3 Despersonalización $<3$ Realización Personal $>1$ Agotamiento Emocional $<3$ Despersonalización = 3 Realización Personal $>1$ Agotamiento Emocional $<3$ Despersonalización $<3$ Realización Personal =1

La persona se encuentra en riesgo de presentar burnout si el síntoma de Agotamiento Emocional o el de Despersonalización reflejan un valor Alto (3). Esta condición también se presenta sólo si la Realización Personal es Baja (1).

- Tendencia:

Agotamiento Emocional=3 Despersonalización < 3 Realización Personal =1 Agotamiento Emocional<3 Despersonalización = 3 Realización Personal =1 Agotamiento Emocional=3 Despersonalización = 3 Realización Personal >1

La persona presenta una tendencia a desarrollar el burnout cuando dos de los síntomas tienen un puntaje elevado, como es el caso del Agotamiento Emocional y la Despersonalización, o también si la Realización Personal presenta el puntaje mínimo. 
- Burnout:

Agotamiento Emocional=3 Despersonalización = 3 Realización Personal =1

En el tercer caso, los tres síntomas están presentes. En consecuencia, la persona ya desarrolló el síndrome de burnout.

\subsubsection{Confiabilidad y Validez}

\subsubsection{Confiabilidad y Validez original}

En relación a la confiabilidad y validez, es necesario revisar en primer lugar, los datos de la versión original traducida al idioma español por TEA ediciones en el año 1997.

En cuanto a la confiabilidad, estimada la consistencia interna mediante el coeficiente de alfa de Cronbach en una muestra de 1316 casos se obtuvieron los siguientes índices: 90 en Agotamiento Emocional, .79 en Despersonalización y .71 en Reducida Realización Personal. En otros dos análisis originales se empleó también el procedimiento de test-retest. En el primero se empleó una muestra de 53 graduados universitarios en servicios sociales con un intervalo de dos a cuatro semanas entre ambas aplicaciones, y los índices de fiabilidad fueron de .82 para Agotamiento Emocional, .60 en Despersonalización y .80 en Reducida Realización Personal. En el segundo, se empleó una muestra de 248 profesores y un intervalo de un año entre el momento del test y el retest, y se hallaron índices de $.60 ; .54$ y .57 respectivamente (Maslach y Jackson, 1997).

Asimismo, los autores obtuvieron evidencias de validez y realizaron tres tipos de análisis en los que las puntuaciones del MBI se pusieron en relación con: las evaluaciones del comportamiento hechas por una persona que conoce bien al sujeto examinado, la presencia de algunas características laborales que normalmente provocan estrés y las medidas en otras variables que, por hipótesis, están relacionadas con este estrés (Maslach y Jackson, 1997). 


\subsubsection{Confiabilidad y Validez en Perú}

Para presentar las estadísticas de confiabilidad y validez en Perú es necesario en primer lugar, revisar la investigación realizada por Fernández con profesores, en la cual consideró pertinente analizar las puntuaciones de cada una de las áreas que conforman el instrumento (Fernández, 2002).

En el análisis del área de agotamiento emocional del Inventario de Maslach, la confiabilidad estudiada por medio del coeficiente alfa de Cronbach ascendió a .78, lo que lleva a concluir que los ítems de esta área permiten obtener puntajes confiables. En cuanto al área de despersonalización, la confiabilidad evaluada a través del coeficiente alfa de Cronbach es de .76, razón por la cual los puntajes de esta área también son confiables. Por último, en lo que concierne al área de realización personal en el trabajo se observa que el coeficiente alfa de Cronbach es de .74, lo cual significa que los ítems de esta área también permiten obtener puntajes confiables.

Por otro lado, en la investigación de Fernández (2002), se obtuvieron evidencias de validez relacionadas con el contenido, a través del criterio de jueces. Para cuantificar los hallazgos se utilizó el coeficiente $\mathrm{V}$ de Aiken y los resultados indicaron que todos los ítems alcanzan niveles adecuados de significación estadística. También se estudiaron las evidencias de validez referidas a la estructura interna por medio del método intraprueba, efectuándose el análisis factorial confirmatorio. Los resultados alcanzados señalan que el modelo de tres factores alcanza mejores resultados que el modelo independiente, de manera que se observa un estadístico chi-cuadrado (47.01) que no es significativo, y además, los estadísticos encargados de evaluar la adecuación del modelo $(\mathrm{GFI}=.98$ y AGFI $=.95)$, son adecuados, por lo que se concluye que el Inventario de Burnout de Maslach presenta adecuadas evidencias de validez referidas a la estructura interna.

Por otro lado, este instrumento también tiene una adaptación realizada en profesionales de la salud. En la adaptación de Llaja, la cual será utilizada en la presente investigación, el análisis psicométrico consistió en varios aspectos. Los estadísticos de 
confiabilidad se realizaron en dos submuestras del total (313 participantes), Salud y No Salud, haciendo correlación por sexo, y con las 3 escalas del burnout.

En el análisis del área de agotamiento emocional del Inventario de Maslach, la confiabilidad estudiada por medio del coeficiente alfa de Cronbach ascendió a .80, lo que lleva a concluir que los ítems de esta área permiten obtener puntajes confiables. En cuanto al área de despersonalización, la confiabilidad evaluada a través del coeficiente alfa de Cronbach es de .56. Esta subescala tiende a producir resultados menos confiables que las demás escalas, y por lo tanto a observar una mayor probabilidad de fluctuación de los puntajes en los mismos evaluados si la medición de este atributo se hiciese repetidas veces. Por último, en lo que concierne al área de realización personal se observa que el coeficiente alfa de Cronbach es de .72, lo cual significa que los ítems de esta área si permiten obtener puntajes confiables. Cabe resaltar que el número de los ítems también ha influenciado en estos resultados de confiabilidad, ya que este aspecto afecta directamente la magnitud del coeficiente alfa: la escala Despersonalización tiene 5 ítems mientras que las otras escalas ocho y nueve (Llaja, Sarria y García, 2007).

Por otro lado, el nivel de confiabilidad parece estar moderadamente relacionado con la dificultad de los ítems para representar este constructo (Despersonalización), ya que las correlaciones inter-ítems tienden a ser bajas comparándolas con las demás escalas. Las correlaciones inter-ítems promedio es mayor para Agotamiento Emocional, luego sigue Reducida Realización Personal y finalmente Despersonalización; esta secuencia también se repite para los valores mínimo y máximo de las correlaciones inter-ítem. Como indicadores de la homogeneidad de los ítems, los niveles han estado dentro del rango aceptado en la literatura psicométrica (Llaja, Sarria y García, 2007).

En lo que refiere a la discriminación del ítem se puede decir que viene a ser la correlación del ítem con su escala, lo cual permite conocer "el grado en que el ítem puede diferenciar entre una persona que tiene elevado nivel en el atributo frente a otro de más bajo nivel en ese mismo atributo" (Llaja, Sarria y García, 2007, p.40). Respecto a la escala Agotamiento Emocional los estadísticos de confiabilidad por consistencia interna y homogeneidad de ítems han sido favorables. En cuanto a la escala Despersonalización, el ítem 15: No me preocupa realmente lo que ocurre a algunas personas a las que les doy servicio, ha impactado sobre la confiabilidad, pues la correlación es baja .26. Asimismo, en la escala Realización Personal, la correlación 
ítem-test es positiva. Los ítems con baja correlación permanecieron aún dentro de sus escalas respectivas pues tienen validez de contenido. Además la evidencia mostrada es parcialmente conclusiva para decidir su remoción.

Respecto a la estructura interna se aplicó un análisis de componentes principales para extraer el porcentaje de varianza explicada por cada dimensión del burnout. "Una estimación de la unidimensionalidad consiste en la magnitud del primer autovalor para cada factor, en la solución factorial no rotada" (Llaja, Sarria, García, 2007, p.41).

Estos autovalores y sus respectivos porcentajes de varianza retenidos llevan a asumir que los grupos de ítems definidos por las tres subescalas representan para cada una de ellas, solo una dimensión latente. Agotamiento Emocional ha retenido mayor varianza (autovalor=3.59, 39.97\%), mientras que Despersonalización y Realización Personal han alcanzado menor de $40 \%$ de varianza. Teniendo en cuenta lo anterior, el porcentaje de varianza explicado supera el mínimo porcentaje para asumir dimensionalidad.

Para examinar la estructura interna, también se examinó las relaciones entre las escalas; ya que las correlaciones inter-escalas permiten evaluar si cada una representa constructos independientes del burnout. Mientras menor sean las correlaciones, ello significa que las escalas no tienen contenidos redundantes y evalúan aspectos relativamente independientes del burnout Es decir, las correlaciones interescalas aseguran la independencia entre las subescalas. Las correlaciones entre Agotamiento Emocional, Realización Personal y Despersonalización han sido cero y solo la correlación entre Agotamiento Emocional y Despersonalización ha sido estadísticamente significativa en un nivel moderado (Llaja, Sarria y García, 2007).

\subsection{Procedimiento de recolección de datos}

Con la finalidad de obtener la información necesaria para la presente investigación, se diseñó un cuadernillo que incluye una ficha sociodemográfica y el Inventario de Burnout de Maslach (MBI) en la versión de Llaja, Sarria y García (2007) adaptada al contexto peruano, de manera que los participantes pudieran marcar directamente sus respuestas en una sola sesión en un tiempo promedio de 20 minutos. 
De esta manera, se procedió a iniciar el proceso de aplicación del instrumento en cada uno de los establecimientos de salud elegidos, en donde también se coordinó previamente con la Dirección de cada institución para definir horarios donde se pueda aplicar la evaluación. Una vez obtenido el permiso, se aplicó la evaluación.

La prueba se aplicó de forma anónima, y se le explicó cada participante el objetivo de investigación, se les preguntó si estaban dispuestos a participar, y para ello firmaron el consentimiento informado. Luego, cada participante recibió un cuadernillo, el cual contiene la ficha sociodemográfica y la prueba con sus respectivas indicaciones. El evaluador leyó las indicaciones y explicó la manera de marcar las respuestas. Se permitió hacer preguntas durante la evaluación. 


\section{CAPITULO V: RESULTADOS}

A continuación, se detallan los niveles de presencia del Síndrome de burnout (Riesgo, Tendencia, Burnout y Ausencia de burnout), según las variables mencionadas en los objetivos de trabajo. Después, se realiza un análisis para determinar si los datos provienen de una población distribuida normalmente. Por último, se comparan las dimensiones del Burnout (Agotamiento Emocional, Despersonalización y Reducida realización personal), según también las variables del estudio.

\subsection{Niveles de Burnout}

En primer lugar se procedió a obtener las frecuencias y los porcentajes de los niveles de Burnout, que han presentado los participantes. Los datos fueron analizados por medio del programa estadístico SPSS usando técnicas descriptivas e inferenciales. Para el reporte descriptivo se usó el análisis de la distribución de frecuencias, la media y desviación estándar con el propósito de conocer las proporciones de las variables sociodemográficas como sexo, profesión, jornada laboral y tiempo de servicio. Así, se examinó los niveles de Burnout, utilizando los niveles o fases indicadas en el Inventario de Burnout (Llaja, Sarria y Garcia, 2007).

En la tabla 6 se aprecia que, en la muestra general, sólo el 9.5\% manifestó haber desarrollado por completo el síndrome de Burnout. Por otro lado, se aprecia que el $27.0 \%$ se encuentra en riesgo de padecer Burnout, el $14.3 \%$ tiene una tendencia a presentarlo, y el $49.2 \%$ de la muestra no ha desarrollado ningún síntoma del síndrome.

Tabla 6

Niveles de Burnout de la muestra en general

\begin{tabular}{lcc}
\hline \multicolumn{1}{c}{ Niveles } & $\mathrm{n}$ & $\%$ \\
\hline Riesgo & 34 & $27.0 \%$ \\
Tendencia & 18 & $14.3 \%$ \\
Burnout & 12 & $9.5 \%$ \\
No tiene burnout & 62 & $49.2 \%$ \\
\hline
\end{tabular}


Por otro lado, se puede observar en la Tabla 7 que, de acuerdo al sexo, en los hombres se ve que un $21.3 \%$ se encuentra en riesgo de presentar Burnout, un $17.0 \%$ tiene tendencia a presentarlo y un $10.6 \%$ ya cuenta con el síndrome. En las mujeres, se ve que un $30.4 \%$ se encuentra en riesgo, un $12.7 \%$ tiene tendencia y el $8.9 \%$ cuenta con el síndrome ya desarrollado.

Tabla 7

Niveles de Burnout según el sexo

\begin{tabular}{lcccc}
\hline \multirow{2}{*}{ Niveles } & \multicolumn{2}{c}{ Masculino } & \multicolumn{2}{c}{ Femenino } \\
\cline { 2 - 5 } & $\mathrm{n}$ & $\%$ & $\mathrm{n}$ & $\%$ \\
\hline Riesgo & 10 & $21.3 \%$ & 24 & $30.4 \%$ \\
Tendencia & 8 & $17.0 \%$ & 10 & $12.7 \%$ \\
Burnout & 5 & $10.6 \%$ & 7 & $8.9 \%$ \\
No tiene burnout & 24 & $51.1 \%$ & 38 & $48.1 \%$ \\
\hline
\end{tabular}

Asimismo, se puede observar en la Tabla 8 que de acuerdo a la profesión; en los médicos se ve que un $23.5 \%$ se encuentra en riesgo de presentar Burnout, un $15.3 \%$ tiene tendencia a presentarlo y un $12.9 \%$ ya cuenta con el síndrome. En las enfermeras, se ve que un $34.1 \%$ se encuentra en riesgo, un $12.2 \%$ tiene tendencia y solo una de ellas cuenta con el síndrome ya desarrollado.

Tabla 8

Niveles de Burnout según la profesión

\begin{tabular}{lcccc}
\hline \multirow{2}{*}{ Niveles } & \multicolumn{2}{c}{ Médico } & \multicolumn{2}{c}{ Enfermera/o } \\
\cline { 2 - 5 } & $\mathrm{n}$ & $\%$ & $\mathrm{n}$ & $\%$ \\
\hline Riesgo & 20 & $23.5 \%$ & 14 & $34.1 \%$ \\
Tendencia & 13 & $15.3 \%$ & 5 & $12.2 \%$ \\
Burnout & 11 & $12.9 \%$ & 1 & $2.4 \%$ \\
No tiene burnout & 41 & $48.3 \%$ & 21 & $51.2 \%$ \\
\hline
\end{tabular}

Asimismo, se observa en la tabla 9 que, según las horas laboradas por semana, de los que pertenecen al grupo que trabaja de 1-18 horas semanales, solo una persona presenta el síndrome. En el grupo que trabaja de 19-36 horas semanales, el 6.1\% se caracteriza como persona con Burnout, y en el grupo de 37-54 horas existe un 
porcentaje de $9.1 \%$ que presenta el Síndrome. Mientras que en los participantes que se desempeñan más de 54 horas semanales, el 16.7\% desarrolla el síndrome por completo.

Tabla 9

Niveles de Burnout según la jornada laboral

\begin{tabular}{lcccccccc}
\hline \multirow{2}{*}{ Grupos } & \multicolumn{2}{c}{ Riesgo } & \multicolumn{2}{c}{ Tendencia } & \multicolumn{2}{c}{ Burnout } & \multicolumn{2}{c}{ No tiene burnout } \\
\cline { 2 - 9 } & $\mathrm{n}$ & $\%$ & $\mathrm{n}$ & $\%$ & $\mathrm{n}$ & $\%$ & $\mathrm{n}$ & $\%$ \\
\hline $1-18$ & 1 & $11.1 \%$ & 0 & $0.0 \%$ & 1 & $11.1 \%$ & 7 & $77.7 \%$ \\
$19-36$ & 15 & $30.6 \%$ & 7 & $14.3 \%$ & 3 & $6.1 \%$ & 24 & $49.0 \%$ \\
$37-54$ & 12 & $27.3 \%$ & 8 & $18.2 \%$ & 4 & $9.1 \%$ & 20 & $45.5 \%$ \\
Más de 54 & 6 & $25.0 \%$ & 3 & $12.5 \%$ & 4 & $16.7 \%$ & 11 & $45.8 \%$ \\
\hline
\end{tabular}

En la tabla 10 que hace referencia al tiempo de años de servicio, se observa que en el grupo que tiene de 1-20 años de servicio trabajando como profesionales de la salud, el $11.9 \%$ ha desarrollado el síndrome, mientras que en el grupo que se ha desempeñado durante 21-40 años, no existe ninguno que lo haya desarrollado, sólo se observa que el $20.0 \%$ tiene un riesgo de poder presentarlo.

Tabla 10

Niveles de Burnout según el tiempo de servicio

\begin{tabular}{lcccc}
\hline \multirow{2}{*}{ Niveles } & \multicolumn{2}{c}{1 a 20 años de servicio } & \multicolumn{2}{c}{21 a 40 años de servicio } \\
\cline { 2 - 5 } & $\mathrm{n}$ & $\%$ & $\mathrm{n}$ & $\%$ \\
\hline Riesgo & 29 & $28.7 \%$ & 5 & $20.0 \%$ \\
Tendencia & 16 & $15.8 \%$ & 2 & $8.0 \%$ \\
Burnout & 12 & $11.9 \%$ & 0 & $0.0 \%$ \\
No tiene burnout & 44 & $43.6 \%$ & 18 & $72.0 \%$ \\
\hline
\end{tabular}

\subsection{Análisis de la normalidad}

Para el reporte inferencial se utilizó el análisis de normalidad de Shapiro-Wilk para conocer si los puntajes obtenidos por los profesionales de los establecimientos de salud provienen de una población en la que se distribuyen normalmente según las variables sociodemográficas. 
En la tabla 11 se hace referencia a los análisis de la normalidad de las dimensiones del Inventario de Burnout de Maslach según sexo. Se observa que las puntuaciones provienen de una población en la que no se distribuyen normalmente, por lo que se usarán estadísticos no paramétricos para las comparaciones entre los grupos según sexo.

Tabla 11

Análisis de Normalidad del MBI según sexo

Shapiro-Wilk

\begin{tabular}{lcccc}
\multicolumn{1}{c}{ Dimensiones } & Grupos & Estadístico & gl & Sig. \\
\hline $\begin{array}{l}\text { Agotamiento } \\
\text { Emocional }\end{array}$ & Masculino & .934 & 47 & .010 \\
& Femenino & .967 & 79 & .039 \\
Despersonalización & Masculino & .850 & 47 & $<.001$ \\
& Femenino & .813 & 79 & $<.001$ \\
& Masculino & .786 & 47 & $<.001$ \\
Realización & Femenino & .844 & 79 & $<.001$ \\
\hline
\end{tabular}

En la tabla 12 se presenta el análisis de la normalidad de las dimensiones del Inventario de Burnout de Maslach según profesión, donde se encontró que la muestra no presenta distribución normal $(\mathrm{p} \leq .05)$, por lo que para las comparaciones según profesión se usarán estadísticos no paramétricos. 
Tabla 12

Análisis de Normalidad del MBI según profesión

Shapiro-Wilk

\begin{tabular}{lcccc} 
Dimensiones & Grupos & Estadístico & gl & Sig. \\
\hline $\begin{array}{l}\text { Agotamiento } \\
\text { Emocional }\end{array}$ & Médico & .890 & 85 & .003 \\
& Enfermera/o & .963 & 41 & .396 \\
$\begin{array}{l}\text { Despersonali } \\
\text { zación }\end{array}$ & Médico & .874 & 85 & $<.001$ \\
Realización & Enfermera/o & .871 & 41 & $<.001$ \\
Personal & Médico & .904 & 85 & $<.001$ \\
& Enfermera/o & .802 & 41 & $<.001$ \\
\hline
\end{tabular}

En la tabla 13 se hace referencia a los análisis de la normalidad de las dimensiones del Inventario de Burnout de Maslach según jornada laboral. Se puede concluir que las puntuaciones de las variables no se aproximan a la distribución normal ( $\mathrm{p} \geq .05$ ) en las dimensiones Despersonalización y Realización Personal para los cuatro grupos etarios y en Agotamiento emocional para el grupo de 19 a 36 años, por lo que se utilizarán estadísticos no paramétricos para la comparación según jornada laboral. 
Tabla 13

Análisis de Normalidad del MBI según jornada laboral

Shapiro-Wilk

\begin{tabular}{lcccc}
\multicolumn{1}{c}{ Dimensiones } & Grupos & Estadístico & gl & Sig. \\
\hline $\begin{array}{l}\text { Agotamiento } \\
\text { Emocional }\end{array}$ & $1-18$ & .942 & 9 & .602 \\
& $19-36$ & .930 & 49 & .006 \\
& $37-54$ & .957 & 44 & .101 \\
Más de 54 & .960 & 24 & .432 \\
Despersonalización & $1-18$ & .609 & 9 & $<.001$ \\
& $19-36$ & .747 & 49 & $<.001$ \\
& $37-54$ & .883 & 44 & $<.001$ \\
Mealización & Más de 54 & .896 & 24 & .017 \\
Personal & $1-18$ & .771 & 9 & .009 \\
& $19-36$ & .808 & 49 & $<.001$ \\
& $37-54$ & .838 & 24 & .010 \\
\hline
\end{tabular}

En la tabla 14 se presenta el análisis de la normalidad de las dimensiones del Inventario de Burnout de Maslach según tiempo de servicio. Se puede observar que en el caso de las 3 dimensiones las puntuaciones de las variables no se aproximan a la distribución normal a nivel poblacional $(\mathrm{p} \leq .05)$, por ello se utilizará estadísticos no paramétricos para las comparaciones según tiempo de servicio. 
Tabla 14

Análisis de Normalidad del MBI según tiempo de servicio

Shapiro-Wilk

\begin{tabular}{lcccc}
\multicolumn{1}{c}{ Dimensiones } & Grupos & Estadístico & gl & Sig. \\
\hline $\begin{array}{l}\text { Agotamiento } \\
\text { Emocional }\end{array}$ & $1-20$ años & .966 & 101 & .010 \\
& $21-40$ años & .948 & 25 & .221 \\
Despersonalización & $1-20$ años & .853 & 101 & $<.001$ \\
& $21-40$ años & .814 & 25 & $<.001$ \\
$\begin{array}{l}\text { Realización } \\
\text { Personal }\end{array}$ & $1-20$ años & .855 & 101 & $<.001$ \\
& $21-40$ años & .687 & 25 & $<.001$ \\
\hline
\end{tabular}

\subsection{Dimensiones del Burnout}

Vistos los niveles de Burnout según la presencia o ausencia del mismo, se procedió a delimitar en qué medida se fueron dando las dimensiones de Agotamiento emocional, Despersonalización y Reducida Realización Personal, de acuerdo a cada variable de estudio y a revisar si existían diferencias estadísticamente significativas.

En el caso de las variables sexo, profesión y tiempo de servicio, conformadas por dos grupos, se aplicó la prueba U de Mann Whitney y como tamaño del efecto a r. Mientras que para la variable jornada laboral, que está conformada por más de dos grupos, se utilizó el estadístico no paramétrico Kruskall-Wallis y r (a partir de valor Z) para el tamaño del efecto en las comparaciones (Cohen, 1988).

En la tabla 15 se observa la comparación de las dimensiones del Burnout según el sexo. Se observa que no existieron diferencias estadísticamente significativas entre el sexo masculino y el femenino con una $\mathrm{p}>.05$. 
Tabla 15

Comparación de medias para cada dimensión del Burnout según el sexo

\begin{tabular}{|c|c|c|c|c|c|c|}
\hline Dimensiones & Grupos & $\mathrm{Rp}$ & $U$ & $\mathrm{Z}$ & $\mathrm{p}$ & $\mathrm{r}$ \\
\hline \multirow{3}{*}{$\begin{array}{l}\text { Agotamiento } \\
\text { Emocional }\end{array}$} & & & 1822.00 & -0.174 & .862 & .02 \\
\hline & Masculino & 62.77 & & & & \\
\hline & Femenino & 63.94 & & & & \\
\hline \multirow[t]{2}{*}{ Despersonalización } & Masculino & 69.40 & 1579.00 & -1.412 & .158 & .01 \\
\hline & Femenino & 59.99 & & & & \\
\hline Realización & & & 1768.00 & -0.451 & .652 & .04 \\
\hline 0 & Femenino & 64.62 & & & & \\
\hline
\end{tabular}

En la tabla 16 se muestra la comparación de las dimensiones del Burnout según profesión, las cuales son médicos y enfermeras, donde se observa que no existieron diferencias estadísticamente significativas entre dichas profesiones con una $\mathrm{p}>.05$.

Tabla 16

Comparación de medias para cada dimensión del Burnout según la profesión

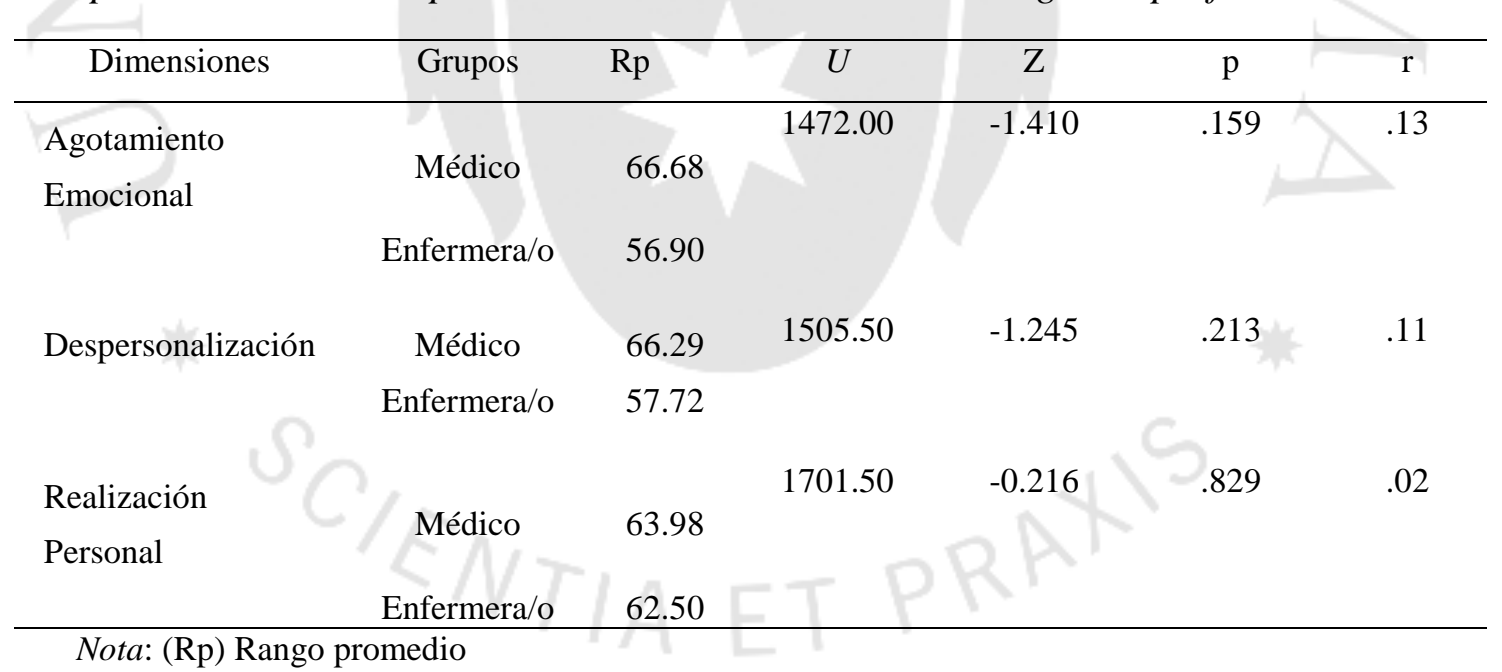

En la tabla 17 se muestra la comparación de las dimensiones del Burnout según la cantidad de horas que trabajan en la semana. Se observa que no existieron diferencias estadísticamente significativas de acuerdo a las horas con una $\mathrm{p}>.05$. 
Tabla 17

\begin{tabular}{ccccc} 
Comparación de medias para cada dimensión del Burnout según la jornada laboral \\
\hline Dimensiones & Grupos & $\mathrm{Rp}$ & Kruskal- & $\mathrm{p}$
\end{tabular}

Wallis

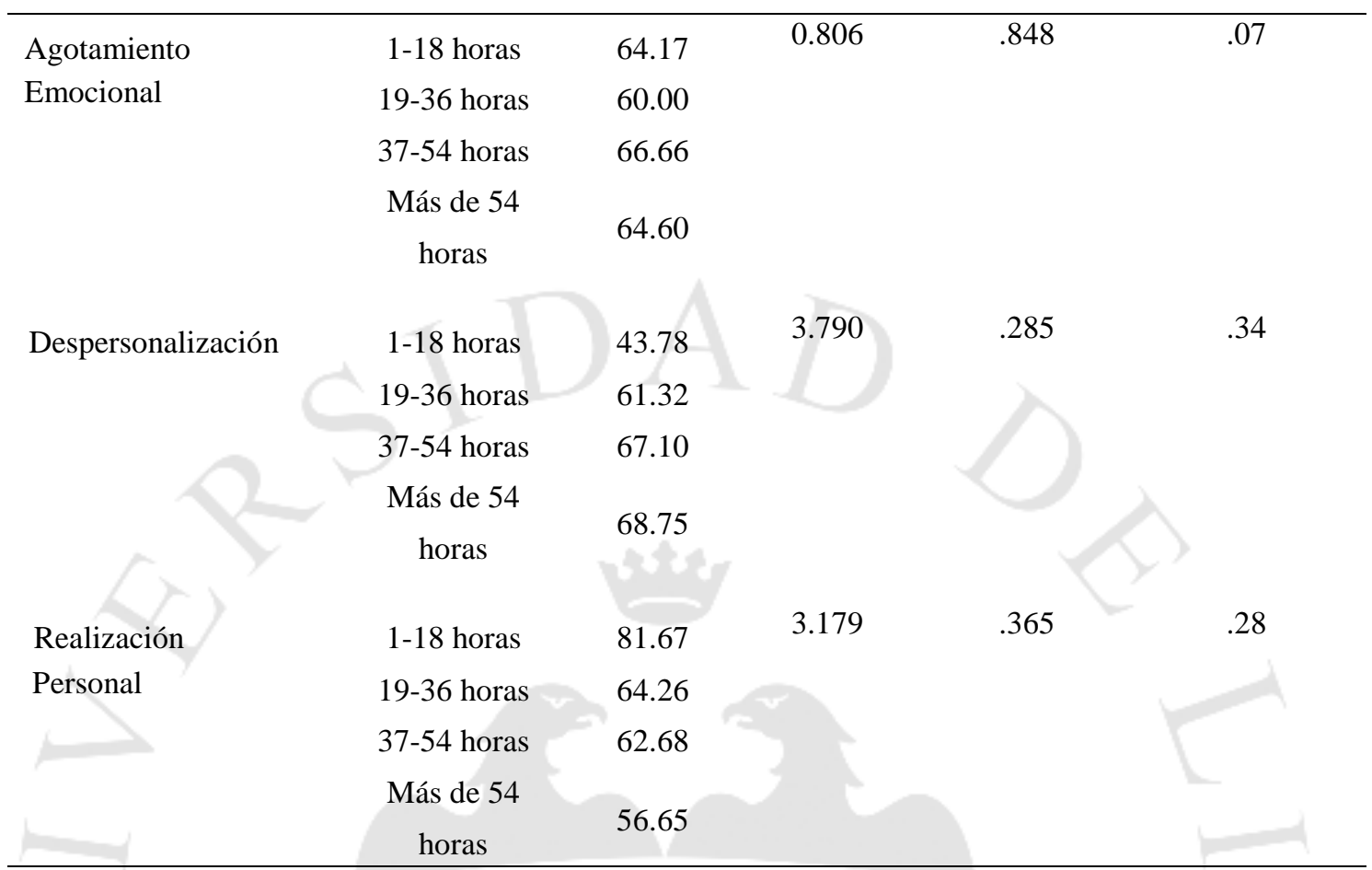

Nota: $(\mathrm{Rp})$ Rango promedio

Por último, en la tabla 18 se observa la comparación de las dimensiones del Burnout según el tiempo de servicio. Cabe resaltar que existieron diferencias estadísticamente significativas en las dimensiones de Agotamiento Emocional y Despersonalización de acuerdo al número de años que llevan trabajando, con una p < .05 .

Por otro lado, también se observa que no existieron diferencias estadísticamente significativas de acuerdo al número de años que llevan trabajando en relación a la dimensión de Realización Personal con una p > .05. 
Tabla 18

Comparación de medias para cada dimensión del Burnout según el tiempo de servicio

\begin{tabular}{lcccccc}
\hline \multicolumn{1}{c}{ Dimensiones } & Grupos & $\mathrm{Rp}$ & $U$ & $\mathrm{Z}$ & $\mathrm{p}$ & $\mathrm{r}$ \\
\hline Agotamiento & $1-20$ años & 68.80 & 727.00 & -3.279 & .001 & .29 \\
Emocional & $21-40$ años & 42.08 & & & & \\
& & & & & \\
Despersonalización & $1-20$ años & 67.44 & 864.50 & -2.456 & .014 & .22 \\
& $21-40$ años & 47.58 & & & .16 \\
Realización & $1-20$ años & 60.54 & 963.50 & -1.847 & .065 & \\
Personal & 21-40 años & 75.46 & & & \\
\hline
\end{tabular}

Nota: (Rp) Rango promedio 


\section{CAPITULO VI: DISCUSION}

Si bien cada profesión tiene niveles distintos de estrés, está comprobado que la labor de los profesionales de la salud está expuesta a distintos estresores, y que por lo general esto va acompañado de periodos de cargas elevadas en el trabajo. Es decir, las actividades de los profesionales de la salud se caracterizan por niveles elevados de estrés ya que, según Martín et al. (2009), estos profesionales se relacionan directamente con la enfermedad, el sufrimiento y otros factores que tienen repercusiones en la vida de una persona.

En el mundo actual, el estrés laboral afecta no solo el bienestar, sino también el desempeño de cada profesional. Razón por la cual, a medida que cada persona esté expuesta de manera más constante a elementos estresores, existe un mayor número de probabilidades que estos desencadenen el síndrome de Burnout.

Para lo cual, es preciso considerar como definición de Burnout, la postulada por Maslach y Jackson (1981), quienes mencionan que el Burnout se configura como un síndrome de agotamiento emocional, despersonalización y falta de realización personal en el trabajo. Asimismo, el agotamiento emocional se ve reflejado cuando el profesional disminuye su capacidad de entrega a los demás, la despersonalización se manifiesta cuando se dan actitudes y sentimientos negativos hacia las personas con las que se tiene contacto en el trabajo, y la falta de realización personal implica una tendencia a auto evaluarse de manera negativa y no sentirse satisfecho con la labor propia.

La actual investigación está centrada en cómo se presenta este síndrome en el contexto limeño, y para ser más específicos, en el contexto de salud pública. El Burnout es un fenómeno que se encuentra latente en la población peruana y prueba de esto son los hallazgos encontrados en las distintas investigaciones realizadas en Lima, donde según Fernández (2010) se puede señalar que los niveles altos de Burnout oscilan entre $5 \%$ y $45 \%$.

Dentro de los establecimientos del primer nivel de atención se encuentran los Policlínicos. Según el MINSA (2004), dichos establecimientos son centros de salud sin internamiento y entre sus funciones principales están las de promoción, prevención, 
recuperación y rehabilitación. En consecuencia, las sedes en las que se ha realizado la presente investigación son Policlínicos de una red asistencial de salud.

Partiendo de lo anterior, se planteó la siguiente pregunta de investigación: ¿Existirán diferencias en las dimensiones de burnout al compararlas según sexo, profesión, jornada laboral y tiempo de servicio, en profesionales de establecimientos de salud del primer nivel de atención de Lima Metropolitana?

La presente sección tiene como fin discutir los resultados a partir de los objetivos de investigación planteados, de allí que a continuación, pasamos a desarrollarlos.

\subsection{Descripción de los niveles de burnout}

Para medir los niveles de burnout de la muestra se hallaron los puntajes de las tres áreas propuestas en el Inventario de Burnout de Maslach. Una vez hallados dichos puntajes se procedió a clasificar cada una de las dimensiones en categorías (alto, medio y bajo). Es importante tomar en cuenta la propuesta de Llaja (2007), quien propone que el burnout se caracteriza por niveles elevados de agotamiento emocional y despersonalización, así como también niveles bajos de realización personal. Adicionalmente, la misma autora señala que si una persona presenta solo una de las dimensiones desarrolladas está en riesgo de padecer burnout, si presenta dos de las dimensiones tiene una tendencia a presentar el síndrome, y si tiene las tres lo ha desarrollado por completo. Por el contrario, si no se manifiesta ninguna de las tres dimensiones, la persona no tiene burnout.

En relación al objetivo de describir los niveles de burnout en profesionales de establecimientos de salud del primer nivel de atención de Lima Metropolitana, los resultados de esta investigación proporcionan que, de acuerdo a lo hallado, el $50.8 \%$ de la muestra ha desarrollado por lo menos algún síntoma de la tríada. Si bien solo el 9.5\% ha desarrollado el síndrome por completo, existe un nivel de estrés elevado, algo que puede entenderse dado el contexto en el cual se desempeñan los profesionales de la salud. De ello se puede inferir que los resultados se orientan en el mismo sentido que la propuesta de Maslach y Jackson, en la medida que el Síndrome de Burnout se presenta principalmente en personas que brindan un servicio asistencial a otros, con los cuales 
muchas veces se vinculan de manera emocional a través de sus problemas, razón por la cual su labor los hace más vulnerables a padecer estrés laboral.

Adicionalmente, se debe tomar en cuenta que la demanda de los pacientes es cada vez mayor, no sólo en el sector público sino también en el privado. De esta manera, la creciente demanda de pacientes trae como consecuencia un incremento de la sobrecarga laboral y como resultado una mayor presencia del síndrome en los establecimientos de salud del primer nivel de atención. Es decir, el aumento de pacientes no ha significado un incremento en la oferta en salud. En muchos casos, los equipos, infraestructura y personal médico no cubren totalmente las necesidades de la población

Asimismo, el porcentaje de burnout en los policlínicos (9.5\%) se contrasta con la cantidad de estrés que se presenta en los demás tipos de establecimientos de salud. Un estudio realizado por Román (2003) estableció la hipótesis de que el nivel de atención diferenciaba significativamente las respuestas de estrés y burnout. Los hallazgos reflejaron que las causas de burnout y el estrés por incertidumbre profesional fueron más altas en el primer nivel. De esta manera, la presente investigación resulta un aporte para el estudio del burnout en los policlínicos, dado que son pocas las investigaciones que incluyan establecimientos de salud del primer nivel de atención, y por lo tanto, se recomienda realizar más estudios comparativos con la finalidad determinar con mayor exactitud en qué contexto se desarrolla más el síndrome.

Con respecto al objetivo de describir los niveles de burnout según el sexo en profesionales de establecimientos de salud del primer nivel de atención de Lima Metropolitana, se encontró que las mujeres han desarrollado el síndrome de burnout en mayor proporción que los hombres. Asimismo, en la presente investigación también se identificó que un mayor porcentaje de mujeres se encuentra en niveles de riesgo y tendencia, lo cual implica que presentan mayor sintomatología del síndrome. Por lo general, las mujeres además del trabajo remunerado que desempeñan tienen responsabilidades fuera del entorno laboral lo cual puede incrementar la cantidad de estresores a los que se encuentran expuestas.

Sin embargo, los resultados obtenidos no son concluyentes dado que no hay un consenso en relación a en qué género prevalece más el burnout. Por un lado, Atance (1997) realizó un estudio en profesionales de atención primaria y atención especializada 
y obtuvo que el perfil epidemiológico de riesgo incluye el que el profesional sea de género femenino. Por lo tanto, los hallazgos de la presente investigación permiten asociar la variable género con los estilos de afrontamiento. Según Choy (2007), las mujeres afrontan las situaciones de estrés con estilos de afrontamiento enfocados en la emoción. En este caso, los esfuerzos del afrontamiento se dirigen a cambiar principalmente la manera en que se interpreta la realidad y con ello también modificar la reacción emocional. Se incluyen estrategias como la evitación, la minimización, el distanciamiento, la atención selectiva, las comparaciones positivas y la extracción de los aspectos positivos que averían en los hechos negativos. El conocer el estilo de afrontamiento utilizado por el género femenino permitirá desarrollar estrategias enfocadas al manejo de las emociones. No obstante, existen investigaciones como la de Aranda (2006), realizada en médicos familiares y cuyos resultados sugieren que los hombres tienden a desarrollar más el síndrome. Adicionalmente, Quiroz y Saco (2003) realizaron una investigación en el Hospital Nacional Sur Este de ESSALUD del Cuzco. En dicha investigación, los resultados también señalaron que existe una asociación significativa entre el burnout y el género masculino. De esta manera, se considera relevante continuar estudiando la variable género con la finalidad de tener una aproximación más exacta de cómo se manifiesta el burnout en distintos grupos.

En cuanto al objetivo de describir los niveles de burnout según la profesión del personal de establecimientos de salud del primer nivel de atención de Lima Metropolitana, los hallazgos reflejan que los médicos muestran un mayor porcentaje de personas que presentan burnout desarrollado que las enfermeras y los enfermeros. Asimismo, también existe un elevado porcentaje de profesionales médicos en riesgo y con tendencia a presentar por completo el síndrome.

Asimismo, los hallazgos se validan con el estudio realizado por Marticorena et al. (2016), quienes señalan que la prevalencia del síndrome de burnout es mayor en médicos con respecto a las enfermeras. Los médicos presentan mayor peso moral por la responsabilidad y autonomía de sus decisiones, lo cual, si bien les otorga más independencia, les genera más contacto con los pacientes y con la enfermedad. Estos hallazgos coinciden con los de Grau et al. (2009) y sugieren que probablemente el personal médico se encuentra más expuesto a factores que incluyen en el burnout como son: mayor sobrecarga de trabajo, privación del sueño, conflictos laborales y bajo 
compromiso organizacional. En base a los resultados, los establecimientos de salud deberán reforzar el trabajo interdisciplinario que se realiza dentro de cada institución.

En relación al objetivo de describir los niveles de burnout según la jornada laboral en profesionales de establecimientos de salud del primer nivel de atención de Lima Metropolitana, si bien no se identificaron diferencias grandes entre los grupos estudiados, el grupo de profesionales que se ha desempeñado en el rango de 19-36 horas semanales es el que presenta más síntomas de Burnout pero no llegan a desarrollar el síndrome. Por otro lado, los profesionales de la salud que trabajan de 3754 horas semanales o más, tienden a desarrollar el síndrome por completo. Al revisar la investigación de Barría (como se citó en Llaja, 2006), se encontró que una jornada de trabajo de más de 8 horas en el mismo lugar, incrementa la probabilidad de aparición del burnout.

Adicionalmente, Atance (1997) señala que la sobrecarga laboral puede producir una disminución de la calidad de los servicios ofrecidos a nivel cualitativo y a nivel cuantitativo. Por otro lado, Guillen (2000), halló que una de las consecuencias de presentar el síndrome de burnout se puede manifestar a nivel conductual con comportamientos inadecuados relacionados con el trabajo y con la organización, presentándose conductas como agresividad, inhibición, cambios del estado de humor, etc. Además, se puede presentar absentismo laboral, lentitud en el desempeño, disminución de la calidad y cantidad en el rendimiento laboral. Por lo tanto, uno de los focos de intervención debe orientarse hacia las personas que presentan alguna de las conductas mencionadas con la finalidad de determinar que estrategias pueden reducir la sensación de sobrecarga laboral que presentan. Asimismo, el intervenir sobre los profesionales afectados beneficia a los pacientes dado que reciben un servicio adecuado y presentan una mejor sensación de bienestar.

Con respecto al objetivo de describir los niveles de burnout según tiempo de servicio en profesionales de establecimientos de salud del primer nivel de atención de Lima Metropolitana, dentro de los resultados se observó que los profesionales de salud que tienen menor tiempo ejerciendo su labor (1-20 años), presentan mayores niveles de Burnout. Según Guido (2006), los profesionales de salud con altos niveles de Burnout están asociados con menos años de ejercicio profesional, lo cual se ve reflejado en la muestra estudiada. El contar con menos años en el campo y poca experiencia frente a 
situaciones estresantes propias de la profesión aumenta las probabilidades de la aparición del síndrome. Adicionalmente, Choy (2007) encontró que los más jóvenes utilizan con más frecuencia el estilo de afrontamiento enfocado en la emoción, lo cual conlleva que en algunos casos no controlen sus emociones y se distraigan cognitiva y conductualmente. Por otro lado, en relación a la edad, se considera que puede existir un periodo de vulnerabilidad dado que sería el período en el cual se produce la transición de las expectativas idealistas hacia la práctica cotidiana (Atance, 1997). De esta manera, los profesionales de la salud en sus primeros años de labor, aprenden durante este tiempo que en algunos casos las recompensas personales, profesionales y económicas no resultan ser las prometidas y esperadas por ellos.

Finalmente, Naisberg y Fenning (1991), encontraron que los profesionales que más burnout presentan acabarían por abandonar su profesión, por lo que los médicos y enfermeras con más años en su trabajo serían los que menos burnout presentaron y por esta razón siguen vigentes en sus labores. Es decir, los hallazgos de Naisberg y Fenning soportan los resultados del presente estudio.

\subsection{Contraste de las hipótesis de investigación}

En la presente sección se analizan los resultados con fines de contrastar las hipótesis planteadas.

En primer lugar, respecto a la hipótesis referida a si existen diferencias estadísticamente significativas entre las dimensiones de agotamiento emocional, despersonalización y reducida realización personal según sexo en profesionales de establecimientos de salud del primer nivel de atención de Lima Metropolitana, se puede observar que al momento de efectuar las comparaciones entre los puntajes de cada una de las dimensiones de burnout según el género, no se han encontrado diferencias estadísticamente significativas entre hombres y mujeres lo cual refuta la hipótesis inicial de la investigación. Los resultados obtenidos se apoyan en los hallazgos de Bulnes (2004) quien realizó una investigación en centros hospitalarios públicos y no encontró diferencias estadísticamente significativas según el género al analizar cada una de las dimensiones.

Si se analiza cada una de las dimensiones se puede observar que según los estudios, la sensación de agotamiento emocional se presenta con mayor frecuencia en 
las mujeres quienes se sienten agotadas y saturadas por el propio trabajo que realizan. Por ejemplo, Atance (1997), afirma que debido a la doble carga laboral que implica la práctica profesional y la tarea familiar, las mujeres tienden a agotarse de manera progresiva. No obstante, el sexo femenino experimenta con mayor frecuencia sentimientos de competencia, eficacia y sienten que están influyendo positivamente en la vida de los pacientes. Es decir, a pesar de sentirse fatigadas, tienen la sensación de estar realizando bien su trabajo y de que su labor tiene repercusiones positivas en las personas que atienden. Por otro lado, en cuanto a la despersonalización, los hombres se comportan de manera impersonal y fría ante los receptores de su servicio o cuidado cuando están expuestos a situaciones estresantes de manera continua. Los resultados se sustentan con los hallazgos de Aranda (2006) quien afirma que los hombres se despersonalizan con mayor frecuencia que las mujeres. Según Vasquez, Maruy y Verne (2014), la carga familiar económica que experimentan algunos hombres podría influir en el estado de percepción de uno mismo y de los pacientes. Por otro lado, las mujeres al experimentar mayor motivación se comportan de manera más cercana con los pacientes. De esta manera, los resultados encontrados en relación a cada dimensión del burnout según el género, no son concluyentes por lo cual se recomienda efectuar más estudios considerando la variable en mención.

En segundo lugar, respecto a la hipótesis de que existen diferencias estadísticamente significativas entre las dimensiones de agotamiento emocional, despersonalización y reducida realización personal según la profesión en el personal de establecimientos de salud del primer nivel de atención de Lima Metropolitana, si se analiza cada dimensión del Burnout de manera individual, se encuentra que los resultados expuestos refutan la hipótesis que propone la existencia de diferencias estadísticamente significativas entre ambas profesiones. Los hallazgos corroboran lo investigado por Ordenes (2004), quien encontró que no existe una diferencia significativa entre las profesiones de salud consideradas en su estudio (médicos, enfermeras, auxiliares paramédicos, kinesiólogos, nutricionistas y tecnólogos médicos), lo que tampoco se ve al analizar cada diagnóstico por separado. Adicionalmente, Gamonal, García, y Silva (2008), señalan que así como los médicos, las enfermeras suelen estar en contacto directo con los pacientes y tienen que soportar duras condiciones de organización del trabajo como por ejemplo los turnos horarios. Asimismo, el personal de enfermería puede atravesar una fase de decaimiento en la que 
la falta de reconocimiento social y de autonomía en su trabajo asistencial son los aspectos clave.

Además, según Llaja, Sarria y García (2007), son los propios sentimientos y conductas de los pacientes, los que pueden ocasionar una mayor exigencia emocional en los profesionales de la salud. El paciente puede estar muy ansioso o sentirse amenazado por la enfermedad, o también por el tratamiento. Por otro lado, los mismos autores refieren que otros factores que pueden influir en el nivel de agotamiento emocional y despersonalización son la naturaleza y gravedad de la enfermedad y los problemas de comunicación con los pacientes. En algunos casos, el personal de salud tiene dificultades para comunicarse directamente con los pacientes, por ejemplo, si se deben dar malas noticias. Si un paciente ha estado enfermo mucho tiempo, la probabilidad de que se produzca una percepción despersonalizada es cada vez mayor. Los esfuerzos de los médicos y enfermeras dejan de tener un efecto significativo sobre la condición del paciente y se generan sentimientos de fracaso e ineficacia, lo cual puede terminar en una baja calidad de asistencia. No obstante, según los resultados de la presente investigación, los médicos y enfermeras pueden llegar a sentirse más motivados y sienten que han realizado de manera eficaz su trabajo cuando logran tratar y curar la enfermedad. De igual forma, resulta relevante tomar en cuenta que se deben implementar programas de intervención enfocados a cada dimensión y orientados al manejo de emociones dado el nivel de exposición a estresores que tienen los profesionales de la salud.

En tercer lugar, en cuanto a la hipótesis de que existen diferencias estadísticamente significativas entre las dimensiones de agotamiento emocional, despersonalización y reducida realización personal según la jornada laboral en profesionales de establecimientos de salud del primer nivel de atención de Lima Metropolitana, se halló que los resultados expuestos refutan la hipótesis que propone la existencia de diferencias estadísticamente significativas entre las horas de trabajo semanales. Según Llaja (2006), la cantidad de contacto que se tiene con las personas receptoras de servicio es considerada una de las variables situacionales para el desarrollo del agotamiento emocional. Es decir, cuanto más tiempo se le dedica al paciente, mayor riesgo de padecer agotamiento emocional presenta el profesional de la salud. Esto se sustenta en los resultados de la investigación donde no existen diferencias estadísticamente significativas, debido a que el nivel en el que los profesionales 
experimentan una sensación mayor de desgaste y pérdida de energía es similar en cada uno de los grupos considerados. Es decir, se debe tomar en cuenta que en muchos casos los profesionales de la salud tienden a experimentar una sensación de agotamiento y desgaste dado que no solo se desempeñan en las instituciones de salud, sino que también pueden ejercer actividades formativas, de docencia o de consulta privada. Según el MINSA (2004) los policlínicos se caracterizan por brindar atención integral ambulatoria médica y se trata de centros de salud sin internamiento En consecuencia, los profesionales de la salud que pertenecen a policlínicos no realizan guardias y pueden disponer de tiempo para trabajar en otra institución de salud. De esta manera, los profesionales de la salud también pueden caracterizarse por presentar sentimientos y actitudes negativas y cínicas hacia la persona con la que trabaja. Por lo tanto, resulta un reto para futuras investigaciones determinar en qué otras actividades está desempeñándose el profesional de la salud con la finalidad de medir el impacto de las mismas en los niveles de burnout que experimenta. Asimismo, de acuerdo a Martín et al. (2009), los profesionales que trabajan más horas pueden estar más expuestos a factores que promueven la aparición del síndrome tales como la responsabilidad que conlleva el trabajo, la falta de organización, la deficiente participación de los profesionales de la salud en los objetivos del sistema las frustraciones frecuentes, la difuminación de responsabilidad, la competitividad, el trabajo sedentario, las prisas y los cambios excesivos en el propio sistema. Ante la situación expuesta, los mismos autores sugieren que un factor protector frente al síndrome es la percepción de apoyo por parte de los compañeros. De esta forma, un adecuado clima laboral constituye un aspecto importante así como también el alternar las actividades propias del trabajo con actividades que promuevan la integración con los demás compañeros de labores. Por otro lado, según López et al. (2006), las jornadas extenuantes provocan privación del sueño, que deteriora el rendimiento laboral, provocando trastornos del carácter e incrementando las posibilidades de error. Por lo tanto, se debe tomar en cuenta que los profesionales de la salud que se desempeñan en sus labores menos horas a la semana tienen un mejor rendimiento y sensación de bienestar hacia sus funciones. Se considera necesario un equilibrio entre las actividades en el centro de salud y el tiempo dedicado a descanso o esparcimiento. De esta manera, se concluye que las diferencias entre los distintos grupos no son estadísticamente significativas por lo que se refuta nuevamente la hipótesis formulada en relación a la jornada laboral de los profesionales de la salud. 
En cuarto lugar, respecto a la última hipótesis que plantea la existencia de diferencias estadísticamente significativas entre las dimensiones de agotamiento emocional, despersonalización y reducida realización personal según el tiempo de servicio en profesionales de establecimientos de salud del primer nivel de atención de Lima Metropolitana, se aceptó únicamente en las dimensiones de agotamiento emocional y despersonalización. Sin embargo, se refuta la hipótesis formulada en relación a la dimensión de realización personal. Resalta el hecho de que los profesionales que han ejercido su labor durante un periodo de tiempo menor o igual a 20 años, en caso manifiesten estrés laboral, pueden experimentar sensaciones de cansancio emocional, y pueden desarrollar en un mayor número de veces actitudes y respuestas cínicas hacia las personas a quienes los trabajadores prestan sus servicios. Según Cherniss (1992), existe una relación entre la poca capacidad del sujeto para desarrollar sentimientos de competencia o éxito personal y el síndrome de burnout. El concepto de autoeficacia percibida, que se refiere a la percepción que tienen las personas sobre sus capacidades para controlar las situaciones que las afectan, puede explicar la manera cómo algunas características del entorno del trabajo llevan al síndrome. Por lo tanto, el logro de metas personales incrementa los sentimientos de autoeficacia, en tanto que el no alcanzarlos puede conducir al desarrollo del síndrome. Dado que en algunos casos los profesionales con pocos años de servicio no han conseguido o logrado sus metas personales, este hecho viene a convertirse en un factor que facilita la aparición del síndrome. Otro aspecto clave situacional en la aparición del burnout es la frustración (Llaja, 2006). Se trata de la diferencia entre las expectativas de éxito y el éxito conseguido. Incluso cuando los profesionales llevan más años trabajando y se han ajustado mejor las expectativas, siguen persistiendo expectativas que son centrales a las profesiones de salud, tales como: curar al paciente, salvar su vida, devolverle la salud. Por ello, en aquellos servicios, en las que tales metas son prácticamente imposibles, los niveles de estrés son especialmente altos.

Sin embargo, dentro de las personas que han ejercido su labor en un lapso menor o igual a 20 años, o de 21 a 40 años, se halló que ambos grupos pueden llegar a experimentar una sensación de competencia personal y tener un autoconcepto positivo. El contar con más experiencia y conocimiento de los procedimientos que se realizan en los establecimientos de salud permite un mejor manejo del estrés. De esta manera, se genera un fenómeno de habituación dado que la exposición a los estímulos estresantes 
se da de manera continua y la reacción es menos intensa. Asimismo, el reconocimiento social y empresarial del trabajo disminuye el desgaste profesional y la probabilidad de sufrir un síndrome de burnout (Martín et al., 2009).

En la presente investigación se evidencia la relevancia de considerar la variable tiempo de servicio como una variable clave dentro del estudio del burnout. El identificar diferencias significativas entre los grupos considerados ayuda a definir una ruta de intervención dirigida hacia aquellas personas que tienen mayor tendencia a manifestar síntomas propios del síndrome. Por ejemplo, en la presente investigación, uno de los focos de intervención está definido por los profesionales que han trabajado menos años, y que por lo tanto, tienen menos experiencia frente a situaciones de estrés. Por otro lado, el estudio de variables como sexo, profesión, y jornada laboral son también determinantes para identificar qué grupos presentan mayor cantidad de burnout a pesar de que no se hayan identificado diferencias estadísticamente significativas entre sus dimensiones.

Finalmente, entre las restricciones o limitaciones encontradas en el presente estudio está, en primer lugar, la poca disponibilidad de tiempo con la que cuentan los participantes. Los profesionales de la salud constantemente están ocupados y en muchas ocasiones no pueden involucrarse en otras actividades debido a la constante demanda de pacientes, razón por la cual hubo personas de la muestra que no pudieron participar de la investigación.

En segundo lugar, al tratarse de instituciones de salud, muchas veces el acceso a las mismas es restringido y cada una maneja políticas que pueden impedir que la investigación se lleve a cabo. Los permisos para realizar estudios en instituciones de este tipo son difíciles de conseguir y se requiere de los mismos para que se pueda llevar a cabo la investigación.

Por último, los horarios de los profesionales de salud en ocasiones no son fijos, lo que posteriormente complicó la posibilidad de aplicar el instrumento de manera colectiva. En la mayoría de casos, la toma de la prueba fue de manera individual, y como consecuencia de esto, la etapa de recolección de datos tomó más tiempo del estimado inicialmente. 
El reto de la investigación del burnout a partir del presente estudio radica en ampliar la muestra y determinar qué grupos son los que tienden a presentar más síntomas e identificar la asociación que existe entre estos síntomas, el contexto social de persona y las características de la organización donde se desempeñan profesionalmente. Es decir, en el caso de los médicos y enfermeras, el identificar los grupos vulnerables dentro de la población va de la mano con el encontrar alternativas de solución en el sector salud para que los profesionales briden una mejor calidad de atención a los pacientes. 


\section{CONCLUSIONES}

- En la muestra general, se halló que el 50.8\% presentó por lo menos algún síntoma de la tríada y el $9.5 \%$ desarrolló por completo el síndrome de Burnout. Asimismo, en relación a la frecuencia de aparición del Síndrome, se observó que este se presenta con una mayor proporción en médicos, en el sexo femenino, en profesionales que trabajan de 37 a 54 horas semanales, y que tienen de 1 a 20 años ejerciendo su labor.

- En relación a las dimensiones de Agotamiento Emocional y Despersonalización, si bien no se encontraron diferencias estadísticamente significativas en las variables sexo, profesión y jornada laboral, se halló que los profesionales de la salud que tienen 20 o menos años de servicio, en situaciones de estrés pueden experimentar mayor cansancio y llegar a tratar a sus pacientes de manera despersonalizada.

- En relación a la dimensión Reducida Realización Personal, los resultados del estudio demuestran que no existen diferencias estadísticamente significativas en las variables sexo, profesión, jornada laboral y tiempo de servicio. 


\section{RECOMENDACIONES}

- En relación a la formación de profesionales de la salud se sugiere que los planes curriculares de las carreras de ciencias de la salud se enfoquen en brindar herramientas para el manejo del estrés a los futuros profesionales.

- En relación al proceso de selección de profesionales de la salud se recomienda que los Centros de Salud evalúen competencias técnicas y habilidades blandas tales como manejo de estrés, tolerancia a la presión, orientación a las personas y trabajo en equipo, al momento de contratar al personal requerido.

- En lo que respecta a las entidades relacionadas a la salud, se recomienda a las mismas tomar en cuenta las dificultades que lleva consigo la labor de los profesionales de la salud, así como promover actividades que comprendan temas de formación académica y capacitación de estos profesionales. Adicionalmente, se sugiere el poder efectuar mejoras pertinentes en las condiciones de trabajo (equipo, instrumentos médicos, flujograma de atención de pacientes) y en la infraestructura de las instituciones con la finalidad de reducir la incidencia del síndrome en el personal de salud.

- En cuanto a la sensibilización, se recomienda concientizar al personal de salud de las instituciones en relación a las consecuencias que trae consigo el estrés laboral en su vida personal y profesional, y también sobre el efecto negativo que puede tener una deficiente calidad de servicio en los pacientes y su manera de afrontar la enfermedad.

- En relación a la promoción de la salud y bienestar para los profesionales de la salud se sugiere en primer lugar; promover talleres de manejo de estrés y conductas asertivas en el sector salud, con la finalidad de disminuir los efectos que se puedan presentar en los profesionales de la salud que se encuentran en 
riesgo o con tendencia a presentar el síndrome de Burnout y así evitar su aparición. En segundo lugar, se sugiere utilizar Terapias Contextuales, promoviendo el uso de Terapia Cognitiva con base en Mindfulness con la finalidad de mejorar el nivel de tolerancia a la frustración y también para aprender a manejar de manera adecuada los niveles de estrés. Asimismo, se recomienda usar la Terapia de Aceptación y Compromiso en los profesionales de la salud que manifiesten una reducida realización personal con la finalidad de conectar a los trabajadores con el origen de su vocación. En tercer lugar, en las personas que presenten niveles elevados de agotamiento emocional y despersonalización, se debe trabajar con programas de emergencia psicológica tales como "Equipos de trabajo" con el propósito de desarrollar herramientas en los profesionales frente al estrés laboral crónico.

- En lo que respecta a la tendencia del burnout en nuestra sociedad, se recomienda intervenir desde las primeras fases del síndrome ya que su aparición se está incrementando no solo a nivel de instituciones de la salud sino también a nivel de otro tipo de organizaciones. En el sector salud, se debe establecer como prioridad el enfocarse en aquellas personas que muestran síntomas iniciales, dado que es importante contar con profesionales de la salud aptos y que puedan atender la alta demanda de pacientes con una adecuada calidad de servicio. En otro tipo de organizaciones, los altos niveles de estrés y su inadecuado manejo trae como consecuencia un bajo nivel de productividad por lo que es fundamental intervenir para disminuir la aparición del síndrome.

- En cuanto a futuras investigaciones, se recomienda replicar la presente investigación en una muestra más amplia para así poder generalizar los resultados obtenidos. También se sugiere estudiar el síndrome en otras ocupaciones para analizar si el perfil varía según profesión. 


\section{REFERENCIAS}

Albaladejo, R., Villanueva, R., Ortega, P., Astasio, P., Calle, M. y Domínguez, V. (2004). Síndrome de burnout en el personal de enfermería de un hospital de Madrid. Revista Española de Salud Pública, 78(4), 505-516. Recuperado de http://www.redalyc.org/articulo.oa?id=17078408

Aranda, C. (2006). Diferencias por sexo, síndrome de burnout y manifestaciones clínicas en los médicos familiares de dos instituciones de salud, Guadalajara, México. Revista Costarricense de Salud Pública, 15(29), 1-7. Recuperado de http://www.scielo.sa.cr/pdf/rcsp/v15n29/3316.pdf

Aranda, C., Pando, M., Salazar, J., Torres, T., Aldrete, M. y Pérez, M. (2004). Factores psicosociales laborales y síndrome de burnout en médicos del primer nivel de atención. Investigación en salud, 6(1), 28-34. Recuperado de http://www.redalyc.org/articulo.oa?id=14260106

Arnold, J. y Randall, R. (2012). Psicología del trabajo: comportamiento humano en el ámbito laboral. México D.F.: Pearson.

Atance, J. C. (1997). Aspectos epidemiológicos del síndrome de burnout en personal sanitario. Revista Española de Salud Pública, 71(3), 293-303. Recuperado de http://www.msssi.gob.es/en/biblioPublic/publicaciones/recursos_propios/resp/revis ta_cdrom/VOL71/71_3_293.pdf

Barria, J. (2003). Síndrome de burnout en asistentes sociales del Servicio Nacional de Menores de la Región Metropolitana. Psykhe, 12(1), 213-226. Recuperado de http://www.psykhe.cl/index.php/psykhe/article/viewFile/332/312

Borbolla-Sala, M. y Domínguez-Sánchez, M. (2007). Síndrome de burnout en personal médico familiar y no familiar del Instituto Mexicano del Seguro Social en Tabasco. Salud en Tabasco, 13(1), 577-583. Recuperado de http://www.redalyc.org/pdf/487/48713105.pdf 
Bulnes, M. (2004). Percepción del clima social laboral y de la eficiencia personal en profesionales de la salud del sector público de la ciudad de Lima. Revista de Investigación en Psicología, 7(2), 39-64. Recuperado de http://revistasinvestigacion.unmsm.edu.pe/index.php/psico/article/view/5106/5499

Camacho-Ávila, A., Juárez-García, A. y Arias, F. (2010). Síndrome de burnout y factores asociados en médicos estudiantes. Ciencia y Trabajo, 12(35), 251-256. Recuperado de http://www.uv.es/unipsico/pdf/CESQT/Externos/2010_Camacho_Avila_et_al.pdf

Cherniss, C. (1992). Long-term consequences of burnout: An exploratory study. Journal of Organizational Behavior, 13(1), 1-11. doi: 10.1002/job.4030130102

Choy, R. (2007). Relación entre las áreas del burnout y los estilos de afrontamiento en una muestra de docentes de niños con problemas de aprendizaje (Tesis para optar el Título de Licenciada en Psicología). Universidad de Lima.

Cohen, J. (1988). Statistical power analysis for the behavioral sciences ( $2^{\mathrm{a}}$ ed.). Mahwah, NJ: Lawrence Erlbaum Associates.

Elkin, A. \& Rosch, P. (1990). Promoting mental health at the workplace: The prevention side of stress management. Occupational Medicine: State of the Art Review, 5(4), 739-754. $\quad$ Recuperado $\quad$ de https://www.ncbi.nlm.nih.gov/pubmed/2237702

ESSALUD (2016). ESSALUD: Principales indicadores de salud 1990-2015.

Recuperado de http://www.essalud.gob.pe/downloads/series_estadisticas_1990_2015_VF.pdf

Estela, L., Jiménez, C., Landeo, J., Tomateo, J. y Vega, J. (2010). Prevalencia de síndrome de burnout en alumnos del séptimo año de medicina de una universidad privada de Lima, Perú. Revista de Neuro-Psiquiatría, 73(4), 147-156. http://dx.doi.org/10.20453/rnp.v73i4.1700

Faul, F. Erdfelder, E. Lang, A. \& Buchner, A. (2007). Statistical power analyses using G*Power 3.1: Tests for correlation and regression analyses. Behavior Research Methods. 41(4), 1149-1160. doi:10.3758/BRM.41.4.1149 
Ferguson, C. J. (2009). An effect size primer: A guide for clinicians and researchers. Professional Psychology: Research and Practice, 40(5), 532-538. Recuperado de http://psychology.okstate.edu/faculty/jgrice/psyc5314/AnEffectSizePrimer_2009.p $\mathrm{df}$

Fernández, M. (2002). Realidad psicosocial del maestro de primaria. Lima: Fondo de Desarrollo Editorial.

Fernández, M. (2008). Burnout, autoeficacia y estrés en maestros peruanos: tres estudios fácticos. Ciencia y Trabajo, 10(30), 120-125. Recuperado de https://www.researchgate.net/publication/229019413_Burnout_autoeficacia_y_estr es_en_maestros_peruanos_tres_estudios_facticos_Burnout_selfefficacy_and_stress_in_peruvian_teachers_three_factual_studies

Fernández, M. (2010). El estrés laboral en los peruanos: hallazgos recientes. Teoría e investigación en Psicología, 19, 37-59. Recuperado de https://www.researchgate.net/publication/281849602_Estres_laboral_en_los_perua nos_hallazgos_recientes_Work_stress_in_Peruvian_Recent_findings

Gamonal, Y. L., García, C., y Silva, Z. I. (2008). Síndrome de burnout en el profesional de enfermería que labora en áreas críticas. Revista de Enfermería Herediana, 1(1), 33-39. http://www.upch.edu.pe/faenf/images/pdf/Revistas/2008/enero/v1n1ao5.pdf

George, D. \& Mallery, P. (2003). SPSS for Windows step by step: A simple guide and reference. Boston: Allyn \& Bacon.

Gil Monte, P. y Peiró, J. (1997). Desgaste psíquico en el trabajo: el síndrome de quemarse. Madrid: Síntesis.

Grau, A., Flichtentrei, D., Suñer, S., Prats, M. y Braga, F. (2009). Influencia de factores personales, profesionales y transnacionales en el Síndrome de burnout en personal sanitario hispanoamericano y español. Revista Española de Salud Pública, 83(2), 215-230. http://dx.doi.org/10.1590/S1135-57272009000200006 
Gomero, R., Palomino, J., Ruiz, F. y Llap, C. (2005). El síndrome de burnout en personal sanitario de la empresa minera de Southern Perú Copper Corporation: Estudio Piloto. Revista médica herediana, 16(4), 233-238. Recuperado de http://www.scielo.org.pe/pdf/rmh/v16n4/v16n4ao1.pdf

Guido, F. (2006). Síndrome de burnout en residentes de cirugía y cirujanos generales de tres hospitales de Lima Metropolitana (Tesis para obtener el Grado de Bachiller en Medicina).Universidad Peruana Cayetano Heredia, Lima.

Guillén, C. (2000). Psicología del trabajo para relaciones laborales. Madrid: McGrawHill.

Guntupalli, K. \& Fromm, R. (1996). Burnout in the internist-intensivist. Intensive Care Medicine, 22(7), 625-630. doi:10.1007/BF01709737

Hernández, R., Fernández, C. y Baptista, M. (2014). Metodología de la investigación. México D.F.: McGraw-Hill.

Karasek, R. (1979). Job demands, job decision latitude and mental strain: Implications for job redesign. Administrative Science Quartely, 24, 285-311. doi: $10.2307 / 2392498$

Keith, D. y Newstrom, J. (2007). Comportamiento humano en el trabajo. México D.F.: McGraw-Hill.

Lazarus, R. \& Folkman, S. (1985). If it changes it must be a process: Study of emotion and coping during three stages of a college examination. Journal of Personality and Social Psychology, 48(1), 150-170. Recuperado de http://webs.wofford.edu/steinmetzkr/teaching/Psy150/Lecture\%20PDFs/Coping.pd f

Leiter, M. \& Maslach, C. (1988). The impact of interpersonal environment on burnout and organizational commitment. Journal of Organizational Behavior, 9, 297-308. doi: 10.1002/job.4030090402

Llaja, V. (2006). Rasgos de personalidad y el síndrome de burnout en el profesional de cuidados intensivos en un hospital de EsSalud de Lima (Tesis doctoral). Universidad de San Martin de Porres, Lima. 
Llaja, V, Sarria, C. y García, P. (2007) MBI Inventario "Burnout” de Maslach \& Jackson. Muestra Peruana. Lima: Pinedo Grafic.

López, A., González, F., Morales, M. y Espinoza, C. (2006). Síndrome de burnout en residentes con jornadas laborales prolongadas. Revista Médica del Instituto Mexicano del Seguro Social, 45(3), 233-242. Recuperado de http://www.medigraphic.com/pdfs/imss/im-2007/im073e.pdf

Mariños, A., Otero, M., Tomateo, J. y Málaga, G. (2011). Coexistencia de síndrome de Burnout y síntomas depresivos en médicos residentes. Estudio descriptivo transversal en un hospital nacional de Lima. Revista Médica Herediana, 22(4), 162-168. Recuperado de http://www.scielo.org.pe/pdf/rmh/v22n4/v22n4ao2.pdf

Marticorena, J., Beas, R., Anduaga, A. y Mayta, P. (2016). Prevalencia del síndrome de burnout en médicos y enfermeras del Perú, ENSUSALUD 2014. Revista Peruana de Medicina Experimental y Salud Pública, 33(2), 241-247. http://dx.doi.org/10.17843/rpmesp.2016.332.2170

Martín, M. J., Hernández, B. M., Arnillas, M. H. y García, M. (2009). Burn-out en el hospital: ¿estamos quemados los médicos? Medicina Balear, 24(3), 29-33. Recuperado de https://dialnet.unirioja.es/descarga/articulo/3215339.pdf

Martínez-López, C. y López-Solache, G. (2005). Características del síndrome de burnout en un grupo de enfermeras mexicanas. Archivos en Medicina Familiar, 7(1), 6-9. Recuperado de http://www.redalyc.org/articulo.oa?id=50770103

Martínez, V., Arenas, M., Paez, A., Casado, E., Ahumada, N., Cuello, S.,...Penna, F. (2005). La influencia de los estilos de personalidad en la elección de estrategias de afrontamiento ante las situaciones de examen en estudiantes de $4^{\circ}$ año de Psicología de la UNSL. Fundamentos en Humanidades, 6(2), 173-194. Recuperado de http://www.redalyc.org/articulo.oa?id=18412610

Maslach, C. y Jackson, E. (1997). Manual del Inventario de Burnout de Maslach. Madrid: TEA Ediciones.

Ministerio de Salud (2004). Resolución Ministerial N769-2004/MINSA. Recuperado de http://www.minsa.gob.pe/transparencia/dge_normas.asp 
Ministerio de Salud (2011). Resolución Ministerial N546-2011-MINSA. Recuperado de http://www.minsa.gob.pe/transparencia/dge_normas.asp

Naisberg, J. \& Fenning, S. (1991). Personality characteristics and propeness to burnout: A study among psychiatrists. Stress Medicine, 7(4), 201-205. doi: 10.1002/smi.2460070402

Ordenes, N. (2004). Prevalencia de burnout en trabajadores del Hospital Roberto del Rio. Revista chilena de pediatría, 75(5), 449-454. http://dx.doi.org/10.4067/S037041062004000500006

Pines, A. \& Maslach, C. (1978). Characteristics of staff burn-out in mental health settings. Hospital \& Community Psychiatry, 29(4), 233-237. doi: 10.1176/ps.29.4.233

Ponce, C., Bulnes, M., Aliaga, J., Atalaya, M. y Huertas, R. (2005). El síndrome del "quemado" por estrés laboral asistencial en grupos de docentes universitarios. Revista IIPSI, 8(2), 87-112. Recuperado de https://dialnet.unirioja.es/servlet/articulo? codigo=2238169

Quesada, J. y Figuerola, J. (2010). Potencia de una prueba estadística: aplicación e interpretación en ecología del comportamiento. Etologuia, 22, 19 - 37. Recuperado de

http://www.academia.edu/18215658/Potencia_de_una_prueba_estad\%C3\%ADstica _aplicaci\%C3\%B3n_e_interpretaci\%C3\%B3n_en_ecolog\%C3\%ADa_del_comport amiento

Quezada, C. (2007). Potencia estadística, sensibilidad y tamaño de efecto: ¿Un nuevo canon para la investigación? Onomazein, 16, 159-170. Recuperado de http://www.onomazein.net/Articulos/16/4_Quezada.pdf

Quintanilla, M. (2004). Prevalencia del síndrome de burnout en las enfermeras de la unidad de paciente crítico del Hospital del Trabajador Santiago de Chile y una propuesta de intervención. Revista Chilena de Medicina Intensiva, 19(1), 33-38. Recuperado de http://medicina-intensiva.cl/revistaweb/revistas/2004/19-12004/full(8).pdf 
Quiroz, R. y Saco S. (2003). Factores asociados al síndrome de burnout en médicos y enfermeras del Hospital Nacional Sur Este de Essalud del Cusco. Situa, 12(23), 1122.

http://sisbib.unmsm.edu.pe/bvrevistas/situa/2004_n23/enPDF/a04.pdf

Rodríguez, C., Oviedo, A., Vargas, M., Hernández, V. y Pérez, M. (2009). Prevalencia del Síndrome de Burnout en personal de Enfermería de dos Hospitales del Estado de México. Fundamentos en Humanidades, 10(19), 179-193. Recuperado de http://www.redalyc.org/articulo.oa?id=18411965011

Román, J. (2003). Estrés y Burnout en profesionales de la salud de los niveles primario y secundario de atención. Revista cubana de salud pública, 29(2), 103-110. Recuperado de http://scielo.sld.cu/pdf/rcsp/v29n2/spu02203.pdf

Sánchez, P. y Sierra, V. M. (2014). Síndrome de Burnout en el personal de enfermería en UVI. Enfermería Global, 33, 252-266. http://dx.doi.org/10.6018/eglobal.13.1.176811

Tuesca, R., Iguarán, M., Suárez, M., Vargas, G. y Vergara, D. (2006). Síndrome de desgaste profesional en enfermeras/os del área metropolitana de Barranquilla. Salud Uninorte, 22(2), 84-91. Recuperado de http://www.redalyc.org/articulo.oa?id=81722204

Vásquez, J., Maruy, A. y Verne. E (2014). Frecuencia del síndrome de Burnout y niveles de sus dimensiones en el personal de salud del servicio de emergencia de pediatría del Hospital Nacional Cayetano Heredia en el año 2014. Lima, Perú. Revista de Neuro-Psiquiatría, 77(3), 168-174. http://dx.doi.org/10.20453/rnp.v77i3.2031

Vizcarra, M. A., Llaja, V., Limo, C. y Talavera, J. (2015). Clima Laboral, Burnout y Perfil de Personalidad: Un estudio en personal asistencial de un Hospital Público de Lima. Informes Psicológicos, 15(2), 111-126. Recuperado de https://revistas.upb.edu.co/index.php/informespsicologicos/article/view/5688/5266

Wright, D. (2003). Making friends with your data: improving how statistics are conducted and reported. British Journal of Educational Psychology, 73, 123-136. doi: 10.1348/000709903762869950 


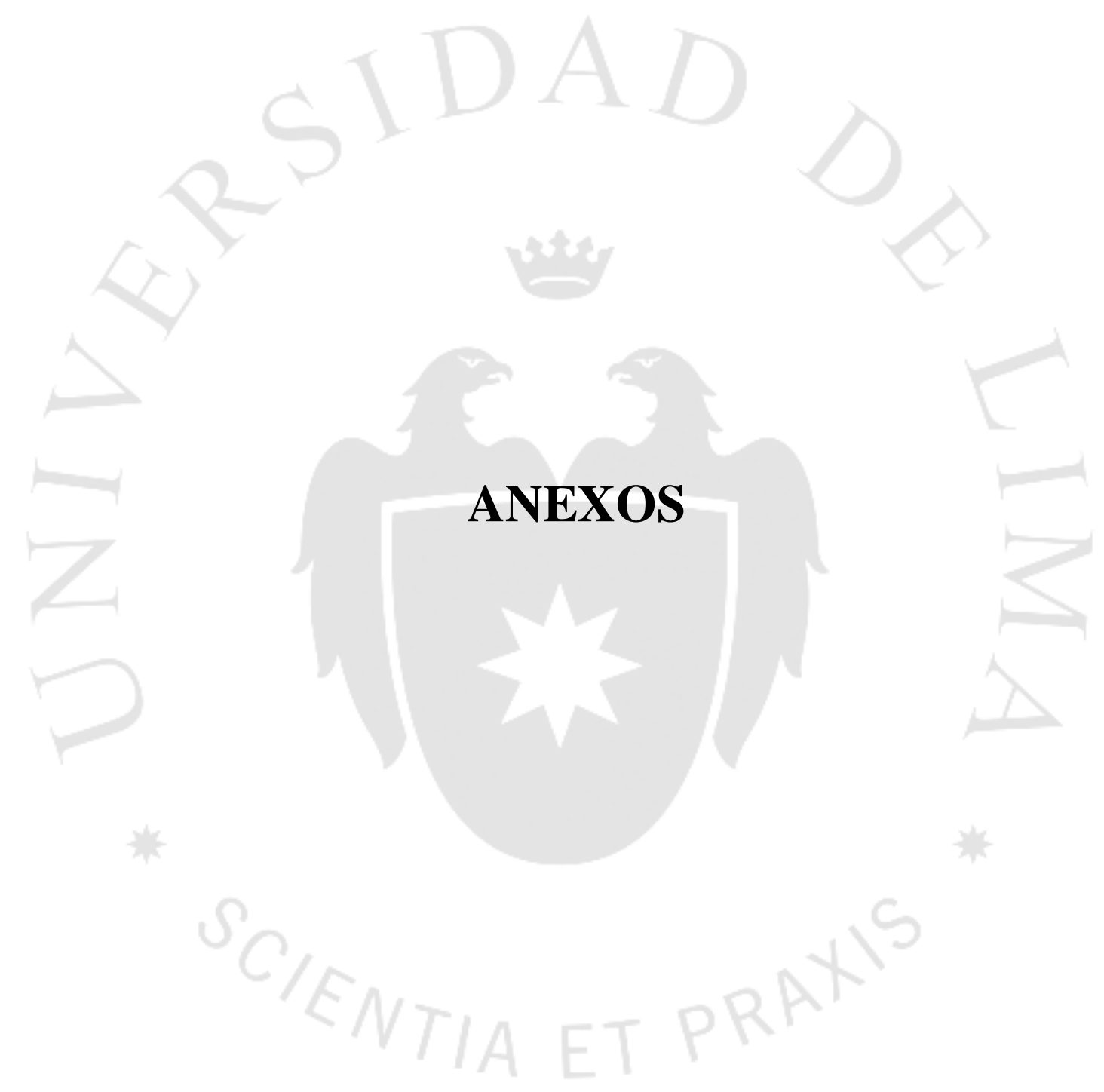




\section{ANEXO 1: Consentimiento Informado}

\section{FICHA DE CONSENTIMIENTO}

El propósito de esta ficha de consentimiento es proveer al participante en esta investigación una clara explicación de la naturaleza de la misma, así como de su rol en ella como participante.

La presente investigación es conducida por Luis Ernesto Nunura, de la Universidad de Lima. La meta de este estudio es medir el nivel de Burnout en profesionales de la Salud.

Si usted accede a participar en este estudio, se le pedirá responder preguntas en una entrevista (o completar una encuesta, tests o lo que fuera según sea el caso). Esto tomará aproximadamente 10 minutos de su tiempo. Lo que conversemos durante estas sesiones se grabará, de modo que el investigador pueda transcribir después las ideas que usted haya expresado.

La participación es este estudio es estrictamente voluntaria. La información que se recoja será confidencial y no se usará para ningún otro propósito fuera de los de esta investigación. Sus respuestas al cuestionario y a la entrevista serán codificadas usando un número de identificación y por lo tanto, serán anónimas. Una vez trascritas las entrevistas, las grabaciones o videos se destruirán.

Si tiene alguna duda sobre este proyecto, puede hacer preguntas en cualquier momento durante su participación en él. Igualmente, puede retirarse del mismo en cualquier momento sin que eso lo perjudique en ninguna forma. Si alguna de las preguntas durante la entrevista le parecen incómodas, tiene usted el derecho de hacérselo saber al investigador o de no responderlas. Desde ya le agradecemos su participación.

Acepto participar voluntariamente en esta investigación, conducida por Luis Ernesto Nunura. He sido informado (a) de que la meta de este estudio es medir los niveles de Burnout en profesionales de la Salud. Me han indicado también que tendré que responder cuestionarios, tests y preguntas en una entrevista, lo cual tomará aproximadamente 10 minutos.

Reconozco que la información que yo provea en el curso de esta investigación es estrictamente confidencial y no será usada para ningún otro propósito fuera de los de este estudio sin mi consentimiento. He sido informado de que puedo hacer preguntas sobre el proyecto en cualquier momento y que puedo retirarme del mismo cuando así lo decida, sin que esto acarree perjuicio alguno para mi persona. De tener preguntas sobre mi participación en este estudio, puedo contactar a Luis Ernesto Nunura al teléfono 992182120.

Entiendo que una copia de esta ficha de consentimiento me será entregada, y que puedo pedir información sobre los resultados de este estudio cuando éste haya concluido. Para esto, puedo contactar a Luis Ernesto Nunura al teléfono anteriormente mencionado. 


\section{ANEXO 2: Ficha sociodemográfica}

\section{Ficha sociodemográfica}

La presente investigación tiene como meta de estudio el medir los niveles de Burnout en profesionales de la salud. Este estudio nos permitirá conocer, de manera científica, la realidad de los profesionales de la salud y realizar las recomendaciones correspondientes.

En este sentido, solicitamos su colaboración para responder a los diferentes componentes de esta encuesta que es totalmente anónima. Muchas Gracias.

1. Sexo: (1)Masculino (2) Femenino

2. Edad

3. Estado civil:
(1) Soltero/a
(2) Casado/a
(3) Viudo/a
(4) Divorciado/a

(5) Separado/a

(6) Conviviente

4. Tiene hijos

(1) Si ¿Cuántos?

(2) No

5. Lugar de nacimiento
(1) Lima
(2) Provincia
(3) Otro

6. Profesión

(1) Médico

(2) Enfermera/o

7. Sede

8. Especialidad

9. Tiempo de servicio

10. ¿Cuántas horas labora por semana?
(1) $1-18$
(2) $19-36$
(3) $37-54$
(4) Más de 54

11. Trabaja en otra institución

(1) Si (2) No ¿Cuál? 


\section{ANEXO 3: Inventario de Burnout}

\section{(adaptado por Llaja, Sarria y García, 2007)}
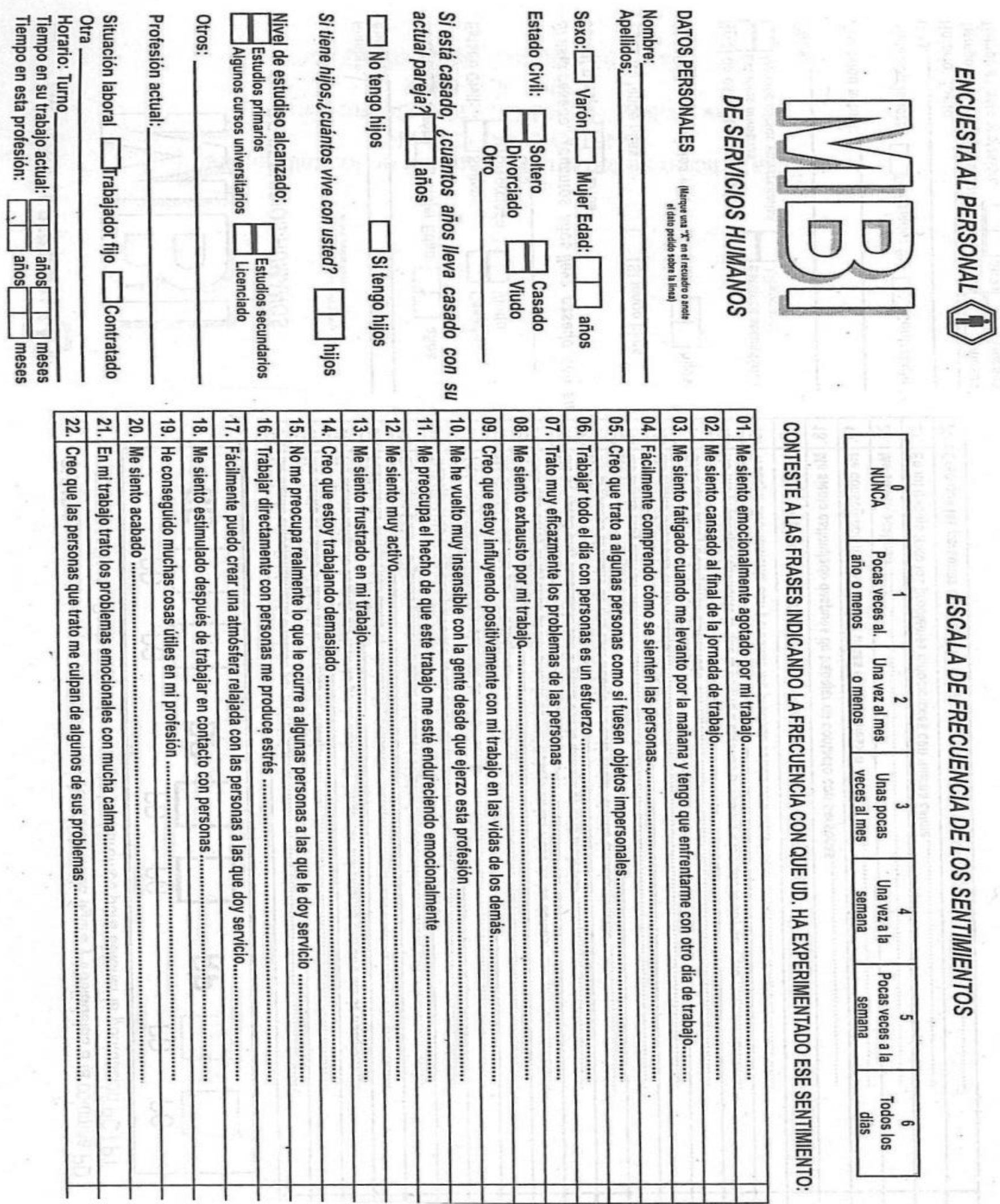


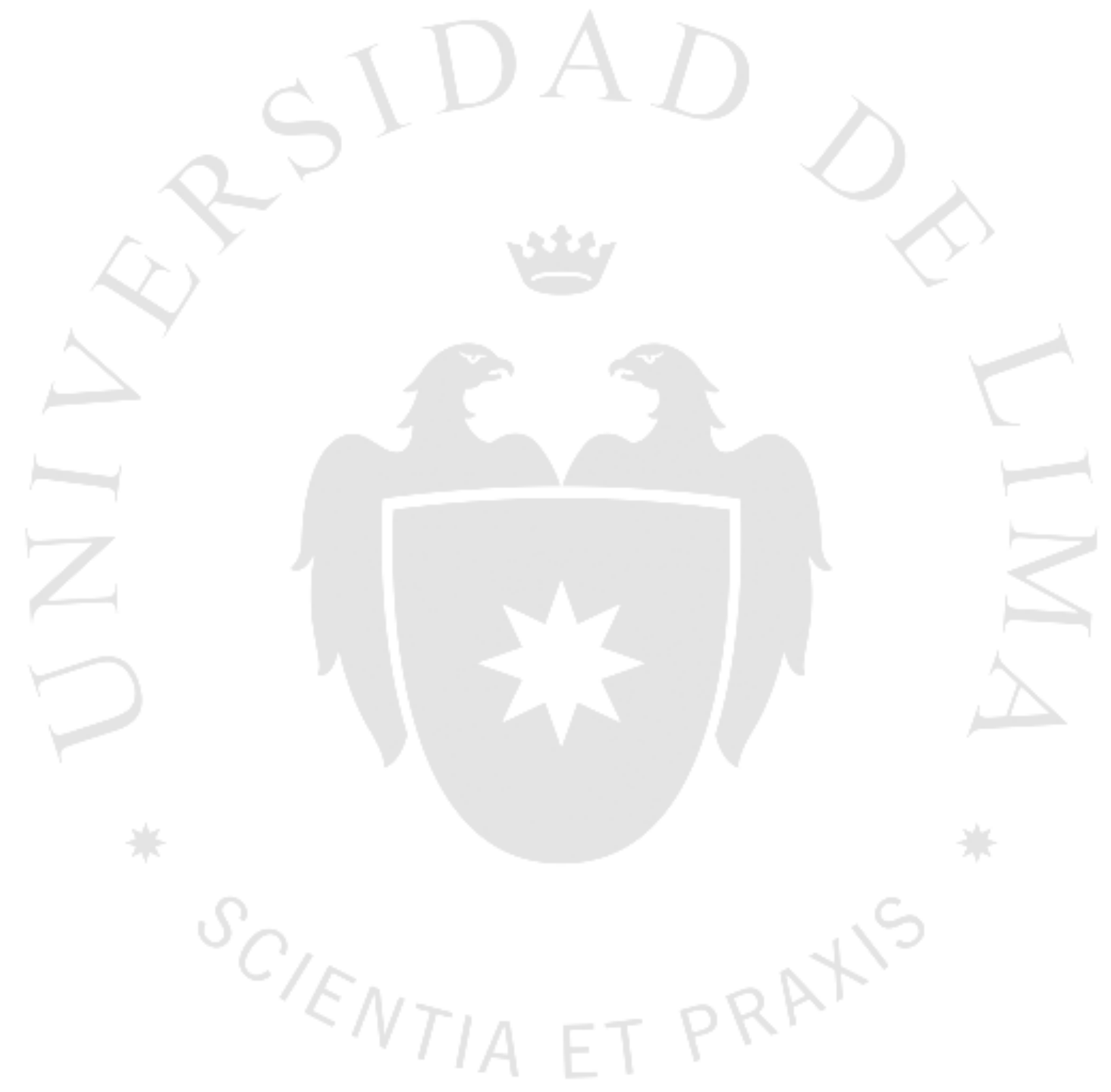

